\title{
الاتفاقات المعلدلة للمسئولية الطبية دراسة مقارنة بين القانونين الإماراتي والإنجليزي
}

Amended Agreements of medical liability

Comparative study between UAE and English law

$$
\begin{aligned}
& \text { الدكتور: أيمن محمد زين } \\
& \text { أستاذ القانون المدني المسـاعد } \\
& \text { جامعة الشارقة - كلية القانون } \\
& \text { قسم القانون الخاص } \\
& \text { تخصص (قانون مدني) }
\end{aligned}
$$




\section{| (الملخص}

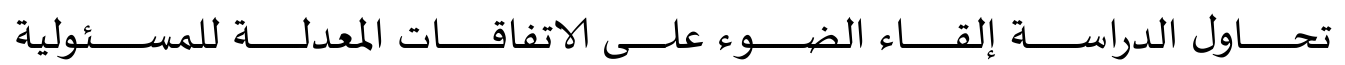

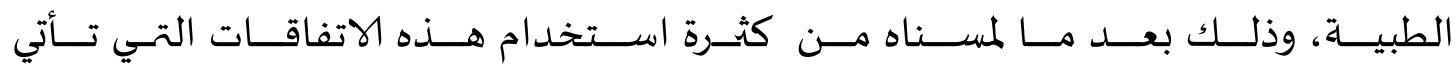

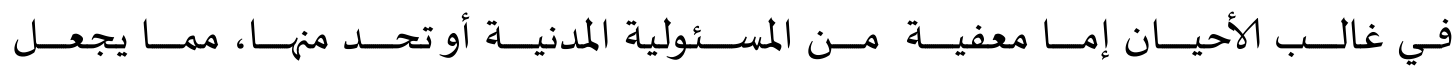
الباحستث يقـــدم هــــه الدراســة في ضـــوء القــانونين الإمــاراتي والإنجليـزي ؛ لتكــون

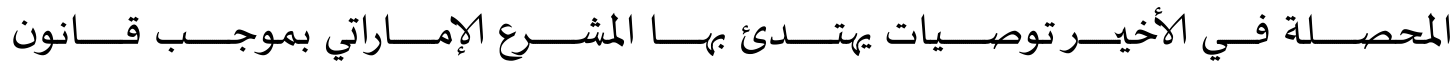
المسئولية الطبية لسنة 77 . أب.

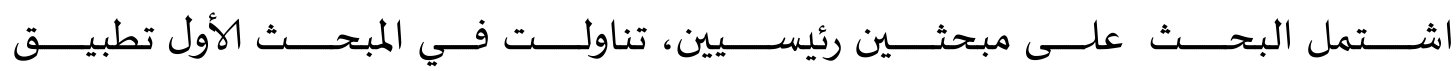

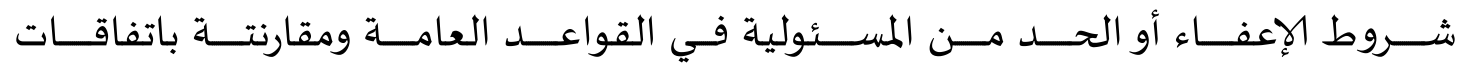

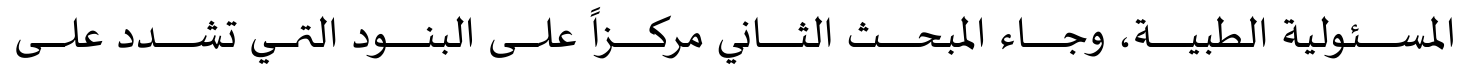

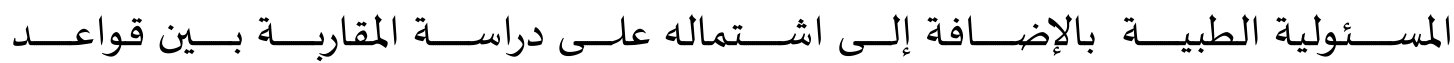
الإعفاء أو الحد من المسئولية الطبية وشروط عقود الإذعان .

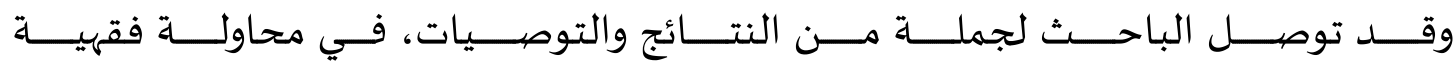

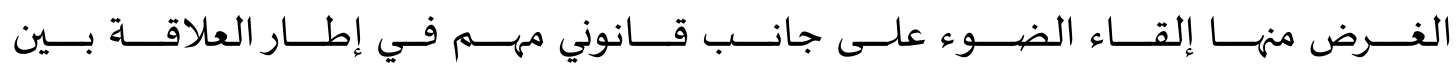
المريض والطبيب.

الكلمات المفتاحية: الاتفاق، المسئولية الطبية، القانون الإماراتي، القانون الإنجليزي 


\section{Research Summary}

The study attempts to focus on the organized agreements of medical liability, after frequent use experience of these agreements, which come often either exempt civil liability or limit, which making the Researcher to submit the study to the light of the laws of the UAE and the law of English, to be collected in the final recommendations to guide the Legislature of UAE according to the Law of Medical Responsibility Y. 17.

The search consist of two main themes, dealt in the first section with the application of the terms of the exemption or limitation of responsibility in the general rules, and comparing with the agreements of Medical Responsibility, the second section focused on items that emphasize Medical Responsibility, because it involves the study of approach between the rules of the exemption or limitation of Medical Responsibility and conditions of Compliance Contracts.

The Researcher end to a number of conclusions and recommendations, in a doctrinal try, purposed to shed light on an important legal aspect, in the framework of the relationship between the Patient and the Doctor.

Key words: The Agreement, Medical Liability, UAE Law, English Law. 


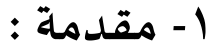

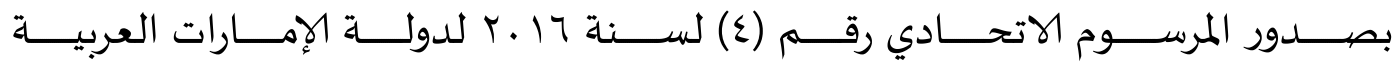

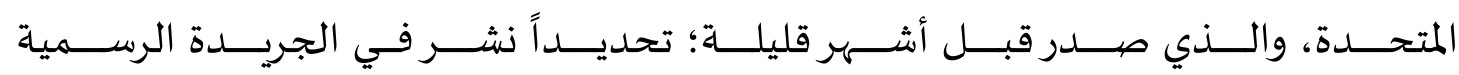

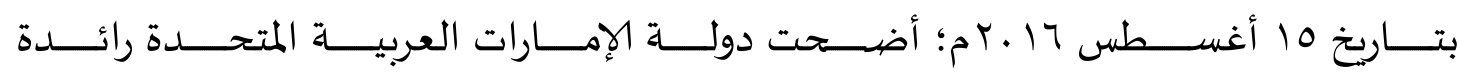
بالفعل في مجال مواكبة المستجدات والمتغيرات المتعلقة بالعمل الطبي.

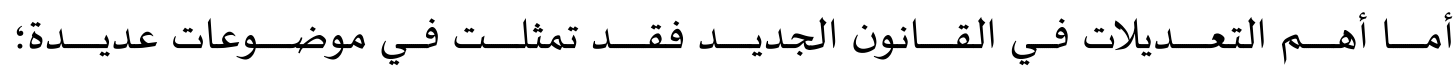

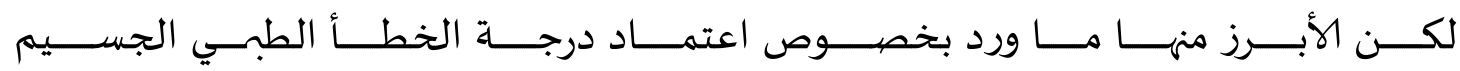

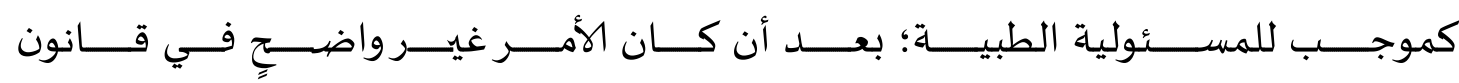

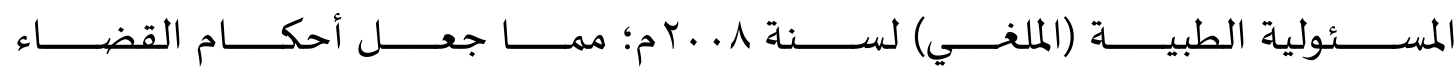

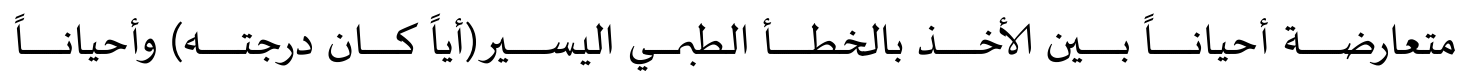

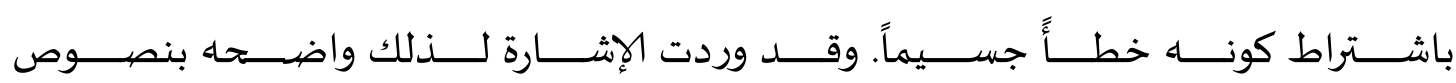

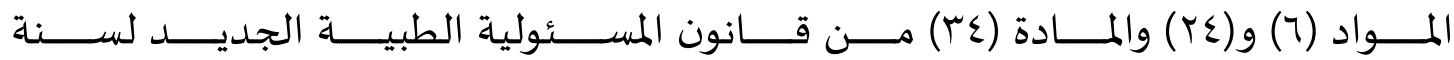
.0 .17

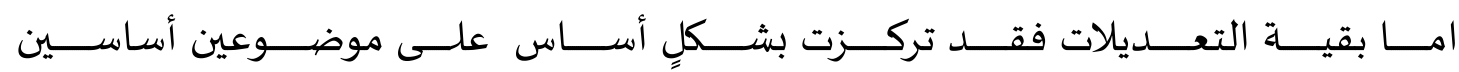

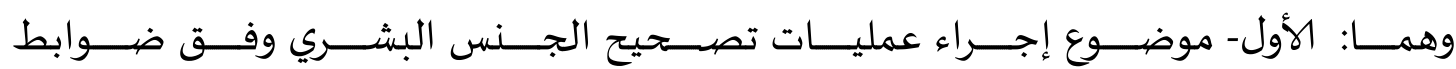
جديدة ارتآها المشرع في الفقرات آT/T/ من المادة (V) من القانون الجديد.

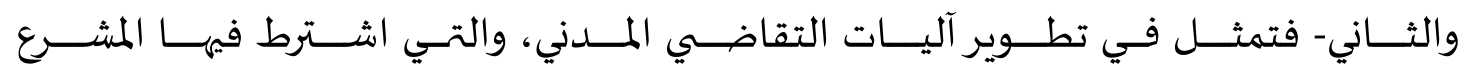

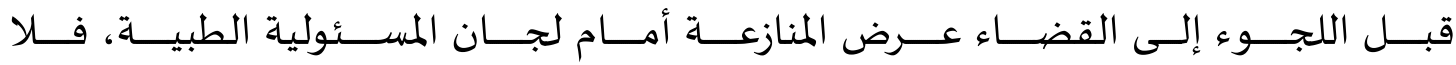

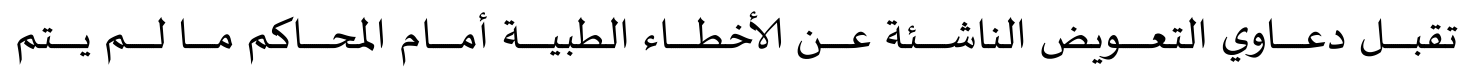

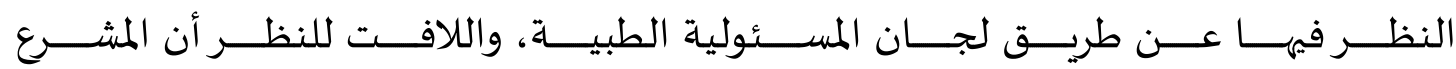

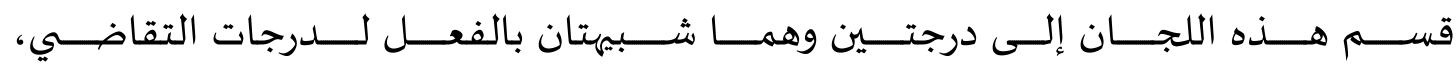

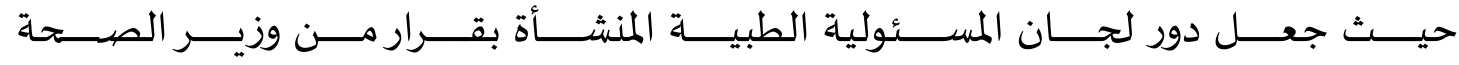

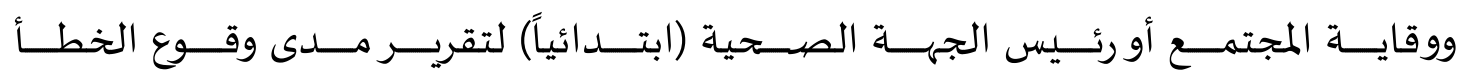

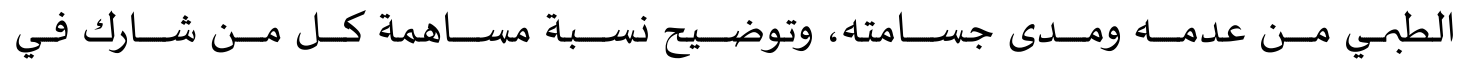

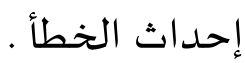




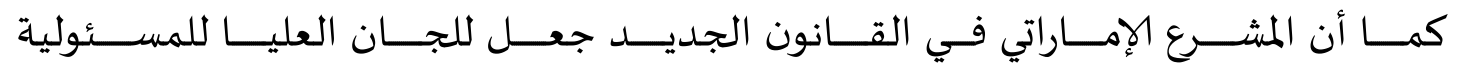

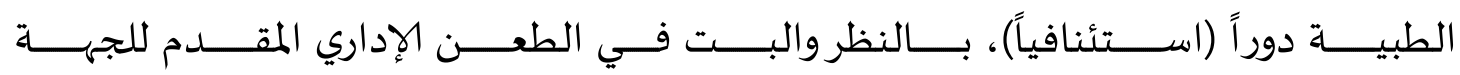

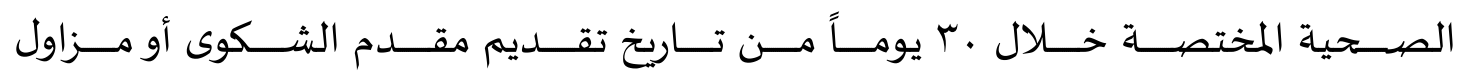

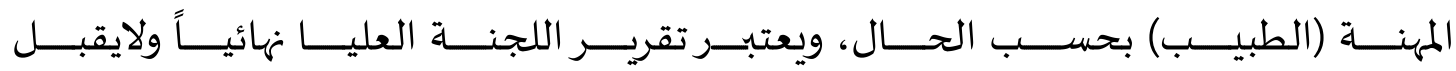
الطعن مرة أخرى أمام أي جهة.

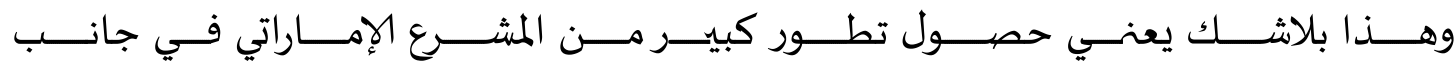

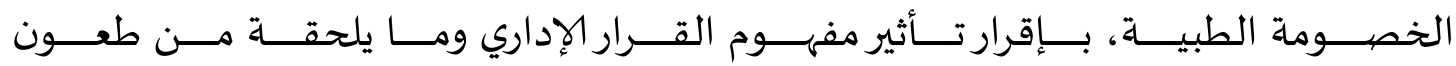

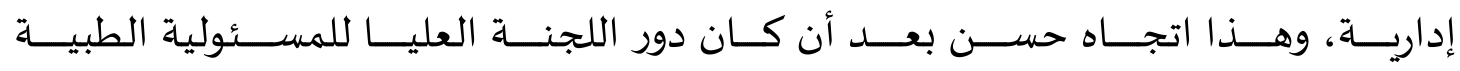

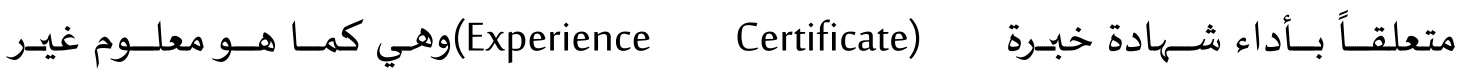

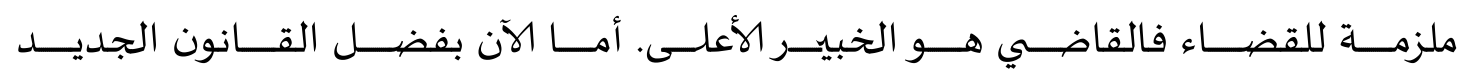

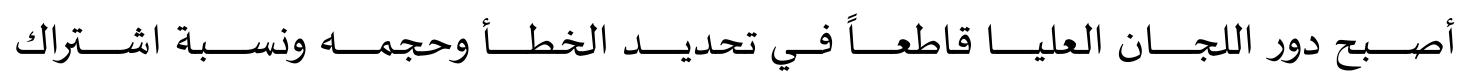

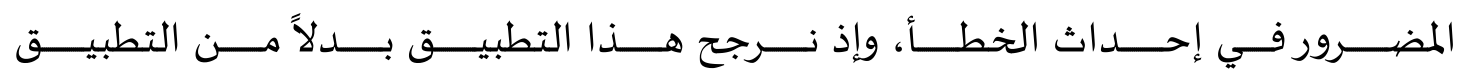

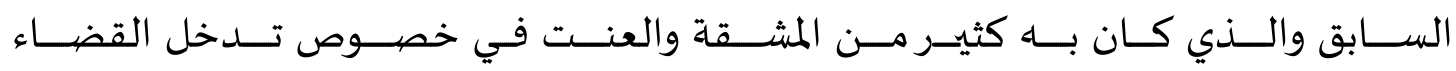

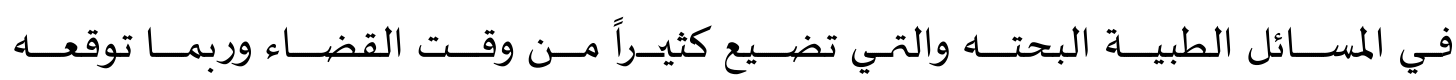
في الذلل نتيجة الاجتهاد في تلك الجوانب .

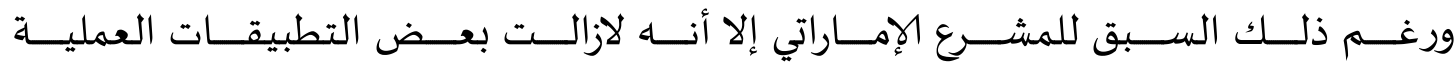

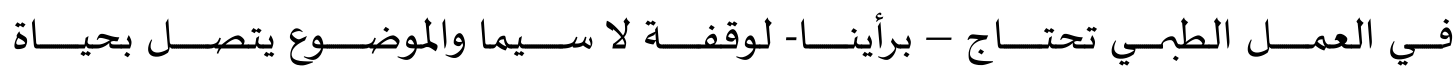

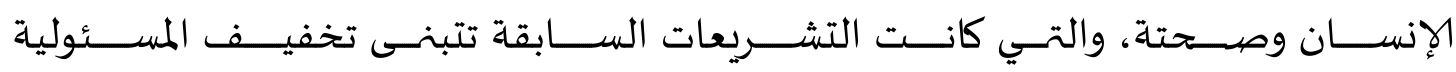

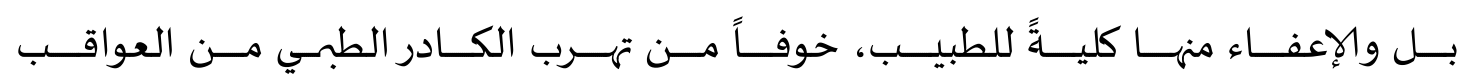

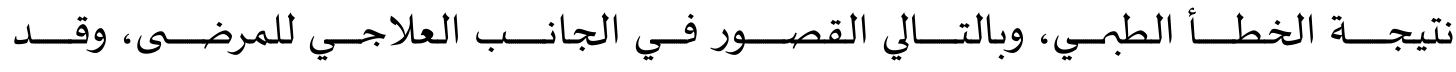

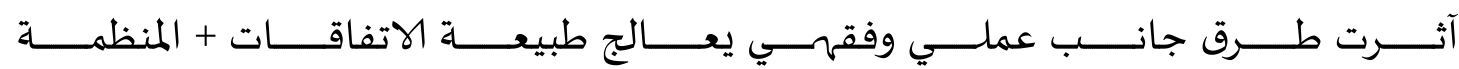

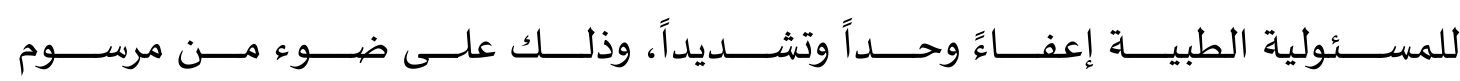

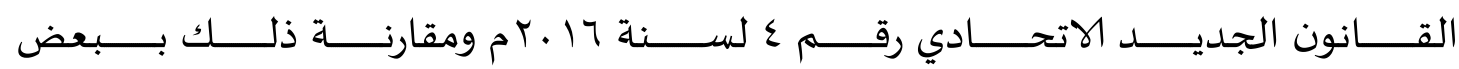

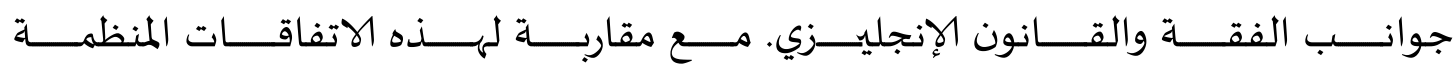
للمسئولية وعقود الإذعان . 


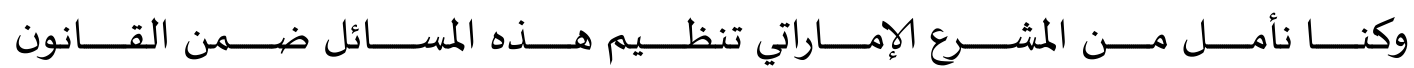

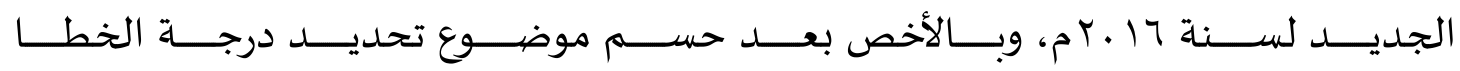

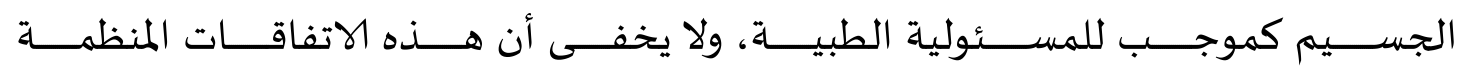

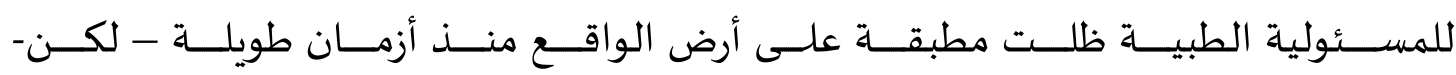

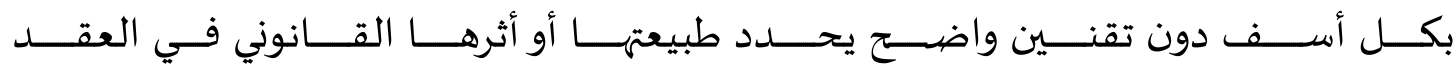

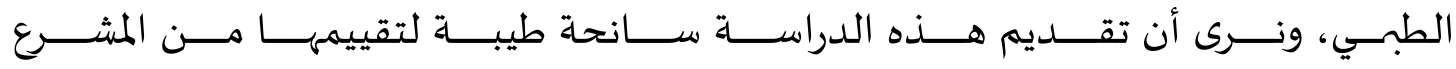
وإقرارها في المستقبل القريب بإذن الله.

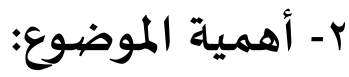

يكتــي موضــوع الاتفاقــات المنظمــة للمســــولية الطبيــة أهميــة كبـرى مــن عــــة زوايا وهي: - 20 - n

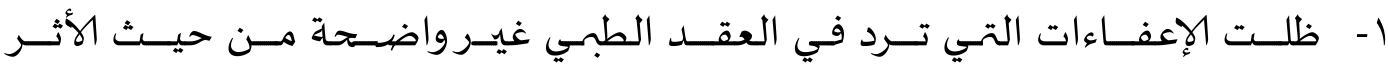

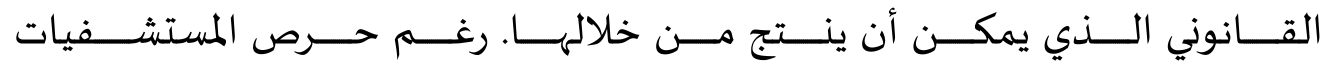

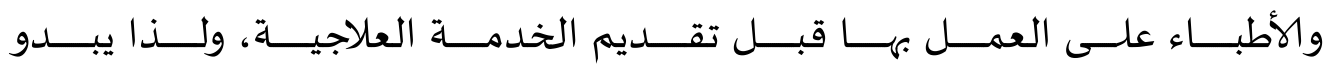

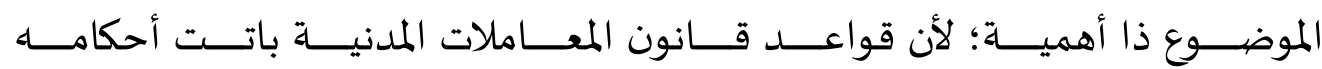
غير كافيه أو متناسبة للتطبيق على النزاعات التي تنشأ.

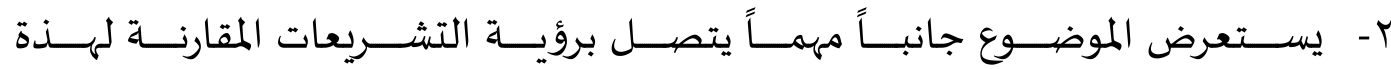

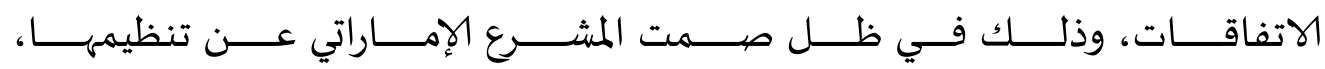

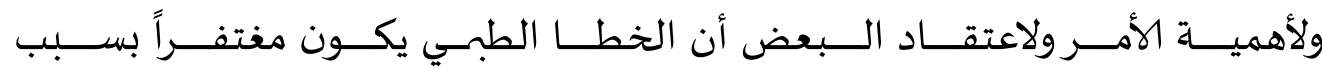

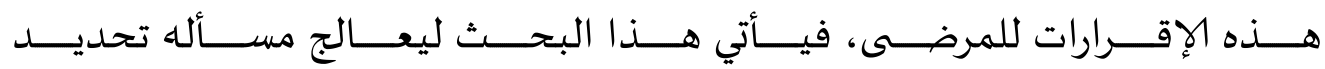
طبيعه هذه البنود . ماره

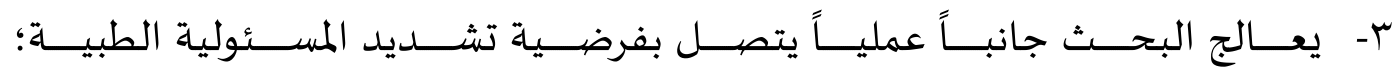

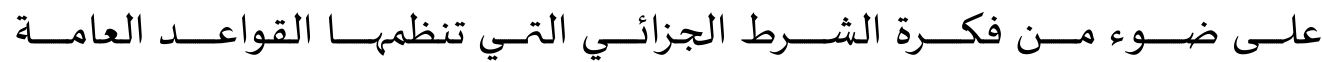
للعقد .

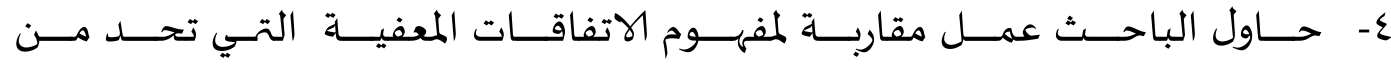

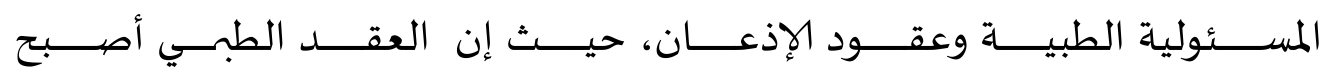




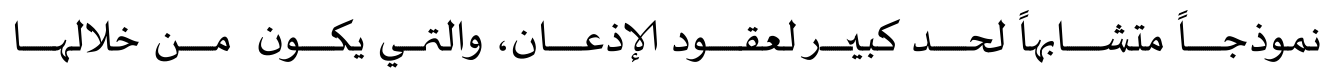

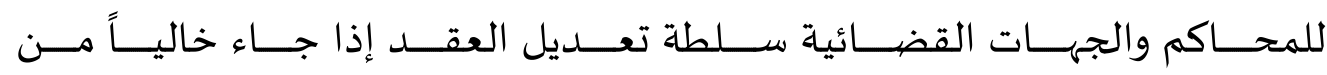
الضوابط التي ينظمها لصيانة حق الطرف المذعن في العقد .

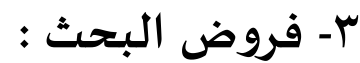

تشتمل هذه الدراسة على فرضيات معينه، تتمثل في الآتي :

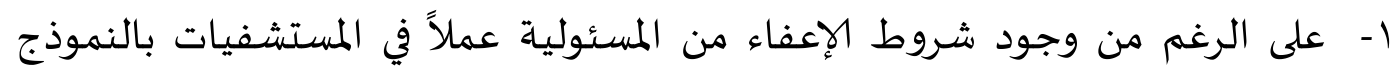

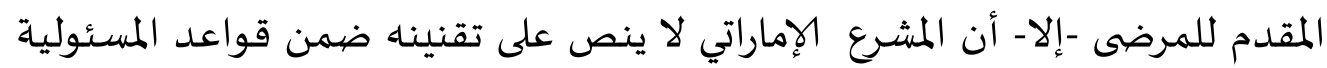

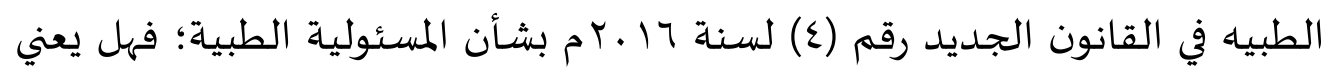
ذلك اعترافاً بتطبيقه وفقاً للقواعد العامه بقانون المعاملات المدنية ؟ أم يعني ذلك الك عدم الاعتداد بصحته r- وهل تعتبر القواعد العامه لتنظيم العقود مناسباً تطبيقها على العقد الطبي في إطار

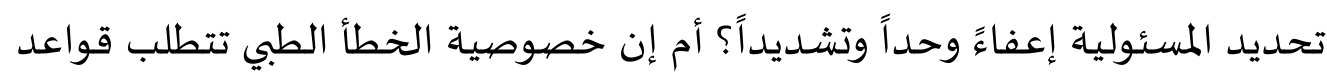
مستقلة في الإعفاء من المسئولية عن القواعد العامة؟ وهل العقد الطبي ذوخصوصية مما لايتناسب معاه تطبيقات القواعد العامها في قانون المعاملات المدنية؟ r- هل يعتبر شرط الإعفاء أو الحد أو تشديد المسئولية في العمل الطبي متوافقاً مع أحكام

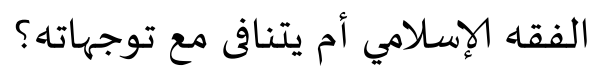
ع- هل تعتبر الوثائق المعفية التي يوقع عليها المرضى لتلقي العلاج هي جزءاً من العقد

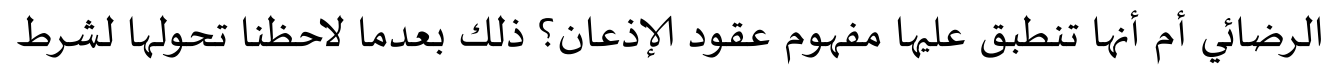
وجوبي لتلقي العلاج للمريض. مما يقتضي الأمر دراسة هذه الشروط وفقاً للقواعد المدان العامه في العقود في شكل مقارنه بين ما يجري عملاً في اتفاقات تحديد المسئولية الطبيه ومقارنتها بشروط تحقق شروط الإذعان وإمكان تطبيق أحكامها على هذه الحالة في حال توصلنا للتطابق بينهما. 


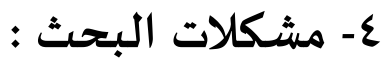

$$
\text { من المشكلات القانونية التي يعالجها البحث: }
$$

ا- - غموض موقف المشرع الإماراتي من عدم تنظيم الشروط المعفية أو التي تحد من

المسئولية الطبية، فلم يجزها ولم يبطلها، وخلا قانون المسئولية الطبية الجديد لسنة

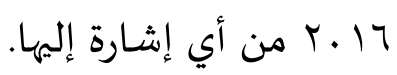

r- القواعد العامه في قانون المعاملات المدنية رقم 0 لسنة إساره إلها 1910 الاتحادي لم توضح سبل الحماية للطرف المذنع، مما تطلب الأمر دراسته وإلقاء الضيوء على التشريع السوداني، والذي عالج المسأله، وإن خلا التشريع من تنظيم مستقل عن المسئولية

الطبية .

r- تشديد المسئولية على المدين بالاتفاق مع الدائن، تبدو مسألة غاية في التعقيد عند

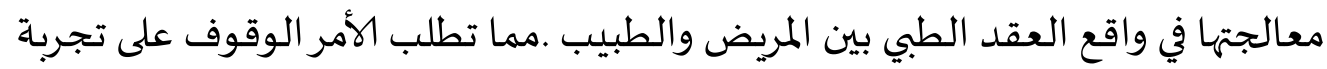

الفقه والقضاء الإنجليزي للاستفادة من المقارنة وصولاً للترجيح. ع- تباين الفقه القانوني الحديث في مدى قبول شروط الإعفاء أو الحد من المسئولية

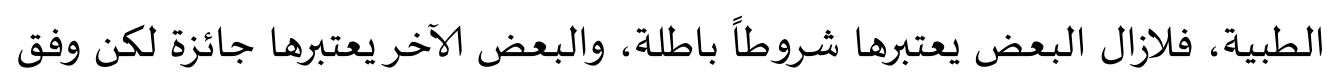

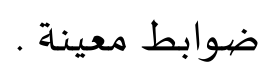

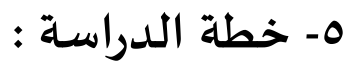

تقتضي خطة الدراسة عرض الموضوع في مبحثين رئيسين أتناول بالمبحث الأول شروط الإعفاء أو الحد من المسئولية في القواعد العامة ومقارنته باتفاقات تعديل المسئولية الطبية، مع مقارنة

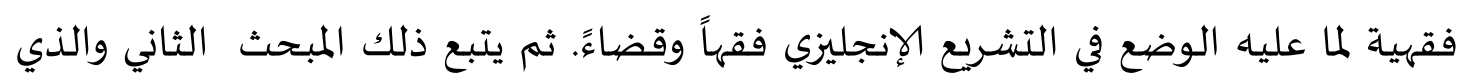

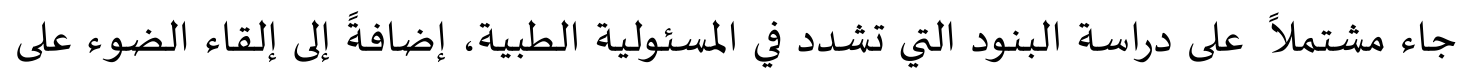
مدى المقاربة بين الاتفاقات المعدلة للمسئولية الطبية وتطبيقات المشرع على عقود الإذعان. وقد قسمت هيكلة البحث على النحو الآتي: 
المبحث الأول :شروط الإعفاء أو الحد من المسئولية في القواعد العامة ومقارنته باتفاقات تعديل المسئولية الطبية.

المطلب الأول: البنود التي تحد أو تعفي من المسئولية الطبية في الفقه والتشريع الإماراتي .

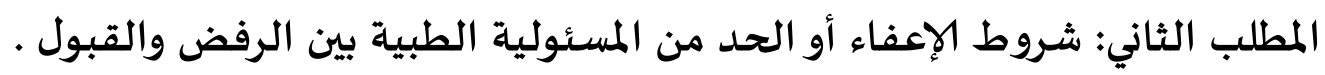
المطلب الثالث: البنود التي تحد أو تعفي من المسئولية الطبية في التشريع الإنجليزي . المبحث الثاني: تشديد المسئولية الطبية، ومدى مقاربة الإعفاء أو الحد من المسئولية الطبية لعقود الإذعان. المطلب الأول: البنود التي تشدد في المسئولية الطبية في القانون الإماراتي . المطلب الثاني: البنود التي تشدد في المسئولية الطبية في القانون الإنجليزي . المطلب الثالث: مدى مقاربة قواعد الإعفاء أو الحد من المسئولية الطبية لعقود الإذعان. الفرع الأول: ماهية عقد الإذعان وطبيعته. الفرع الثاني:مدى مقاربة قواعد الإعفاء أو الحد من المسئولية الطبية لشروط عقود الإذعان. الخاتمة: النتائج والتوصيات.

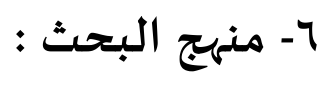

تقوم هذه الدراسة على المنهجين الوصفي والتحليلي، حيث يقوم الباحث بإستعراض الأحكام

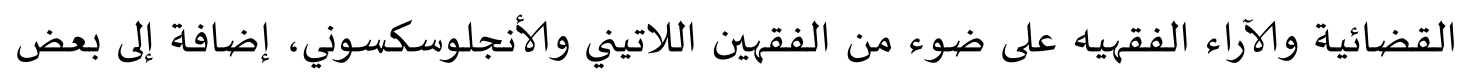
جوانب الفقه الإسلامي المحيطة بالموضوع. وحاولت الترجيح بين الراءاء المتعارضة للاستفادة منها في نتائج وتوصيات البحث. 
جاءت الدراسة لتركز على نطاقين رئيسين وهما: نطاق شخصي ونطاق موضوعي، فالنطاق الشخصي شمل تنظيم العلاقة القانونية بين أطراف هم المريض والطبيب والهيئات الصحية (مستشفيات القطاع الخاص). وذلك باعتبار توافر الصفة التعاقدية المنشئة للمسئولية العقدية في حال الإخلال أكثر التصاقاً بالمستشفى الخاص التهاص .

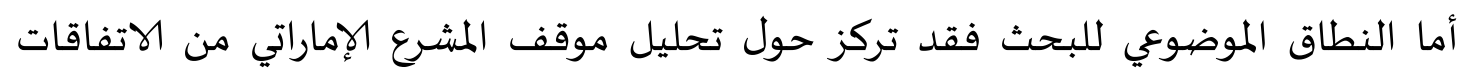
المعدلة للمسئولية الطبية على ضؤ من قانون المسئولية الطبية الجديد لسنة 17 ـب بالإضافة للقواعد العامة الواردة في قانون المعاملات المدنية، وقد اشتملت الدراسة على مقارنة ذلك بموقف التشريع الإنجليزي منها فقهاً وتشريعاً مدعماً بأحدث السوابق والمأحكام الإنجليزية.

\section{مبحث تمهيدي :-}

يعتبر الفقه الأنجلوسكسوني أن واحدة من أهم وسائل دفاع الأطباء في قضايا التقصير المهني هو ما يسهى (بتحمل مسئولية المخاطر) فعادة ما يوافق المشتخلون بمهنة الطب على علاج شخص يعاني من مرض علاجه فيا نسبة من المخاطر، فمثلا إجراء عملية فتح قلب يتوجب

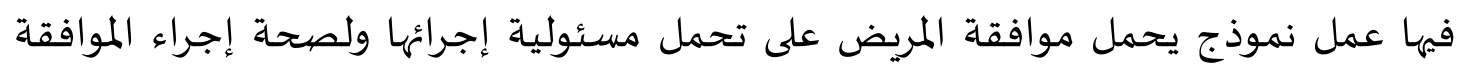
فلابد من علم المريض المدعي لاحقا بهذه المخاطروأن يقبلها بإرادة سليمة حرة وأن يوقع المريض المرئ

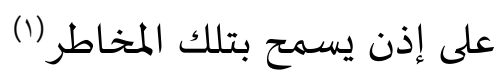
والمبدأ العام أن تحديد نطاق مسئولية الطبيب(r) هنا لابد من تحديدها بصفة عقد مكتوب يوافق عليه المريض وقد وجدنا أن تطبيقات شرط الإعفاء أو الحد من المسئولية في الأنظمة اللاتينية جاءت مقابلة لما يسمى بتحمل مسئولية المخاطر في النظام الأنجلوسكسوني، فكلاهما يؤديان نفس المس

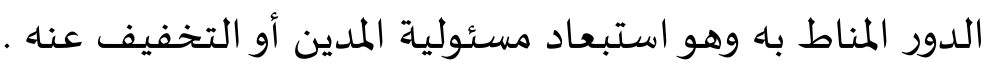
وقبل الخوض في تفصيلات الاتفاقات المنظمة للمسئولية الطبية فلابد من الإشارة إلى نقطتين غاية في الأهمية وهما : - - النقطة الأولى: أن نطاق تعديل المسئولية المدنية بصورة عامة والمسئولية الطبية بصورة خاصة يتوجب أن ينصب على المسئولية العقدية دون المسئولية التقصيرية، 
وما ذلك إلا لاتفاق غالبية الفقه المقارن بأن العقد طالما كان منشؤه إرادة الفرد فلا يوجد ما يمنع ذات الأفراد من تعديل إرادتهم فالأصل حرية المتعاقدين في تعديل قواعد المسئولية العقدية أما المسئولية التقصيرية فنشأت عن طريق القانون؛ لذلك لا يجوز استبعادها أو تعديلها فهي متعلقة بالنظام العام(').

وقد نص المشرع الإماراتي بموجب نص المادة 97r من القانون المدني بقوله: "يقع باطلا كل شرط يقضي بالإعفاء من المسئولية المترتبة على الفعل الضيار" واعتبر المشرع سبب المنع في ذلك لأن إجازته تيسر فتح باب الإضرار بالناس أو يدفعهم إلى عدم التحرز في تصرفهم (ع). - النقطة الثانية: برجوع الباحث سريعا، لبعض مصيادر الفقه الإسلامي فإن هناك إجماعاً على ضمان الطبيب لخطأؤه الطبي، فإن أخطأ لزمه دفع الدياة، لكن في رواية عن مالك أنه ليس عليه شئ،إذا كان من أهل الطب ، أما إن لم يكن من أهل الطب

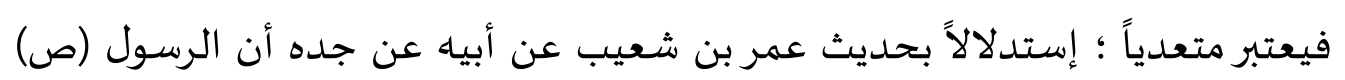
قال: " من تطبب ولم يعلم منـه قبل ذلك الطب فهوضيامن . (ه.).ويرى البعض ان الفقه الإسلامي انقسم إلى فريقين في إطار مشروعية شرط الإعفاء من المسئولية فالفريق الأول منهم لم يجز شروط الإعفاء من المسئولية إلا في نطاق المسئولية المتحققة من السبب الأجنبي. أما الفريق الثاني فقد أجاز شرط الإعفاء من الخطأ البسيط إذا وقع على جسم الإنسان، ويبدو أن القوانين الحديثة جاءت متوافقة مع أحكام الشريعة الإسلامية في هذا المسعى فقد قبلت شروط الإعفاء من الضمان لأنه حق للمالك، وبذلك يملك حق التنازل عنه بينما حرم غالبية الفقهاء الضيمان الناشئ عن التعدي وهو صورة من صور تحقق المسئولية التقصيرية حتى يلتزم الطبيب واجب الحيطة

والحذر عند قياماه بمداواة المرضى (ج).

وعلى كلٍ فلست بصيدد المقارنة الفقهية الإسلامية فلازالت مسألة قبول الفقه الإسلامي لفكرة المسئولية المطلقة مسألة جدلية غير متفق عليها(V). ، والتي ينطبق تطبيقها على المسئولية الطبية ، وهي خارج نطاق البحث لكن الإشـارة إليها يعتبر أمراً غاية في الأهمية عند دراسـة قوانين تهتدي أحكامها بالشريعة الإسلامية . 
وسوف أستعرض في هذا الفصل تطبيقات المشرع الإماراتي للشروط المعدلة والمعفية والمشددة للمسئولية في القواعد العامة والعمل الطبي، وأخصص مبحثاً آخر أستعرض فيه أحكام الفقها والقانون والقضاء الإنجليزي فيما يتعلق بالإعفاء وتشديد المسئولية الطبية.

\section{المبحث الأول}

شروط الإعفاء أو الحد من المسئولية في القواعد العامة ومقارنته باتفاقات تعديل المسئولية الطبية

هناك صعوبة عملية تبدو للناظرفي طبيعة العلاقة بين الطبيب والمريض، فلا يكاد يوجد في الوقت الراهن مستشفى أو مرفق صيحي إلا كان حافلا بوثائق طبية لابد من توقيعها كتابةً من المريض عند التشخيص وأخطرها عند إجراء كثير من العمليات الجراحية المهمة لحياة المرضى

وما أود قوله ربما تكون عقودا نموذجية أوعقد إذعان وهو ما نستعرضها في هذا البحث بالتحليل والمقارنة .

\section{المطلب الأول}

البنود التي تحد أو تعفي من المسئولية الطبية في الفقه والتشريع الإماراتي:

بالنسبة للتشريع الإماراتي فقد وجدت أن المشرع لم ينظم مطلقا أحكاما خاصية بشروط الإعفاء أو الحد من المسئولية ، فقد وجدت إشارة لمنع المشرع الإماراتي لشرط الإعفاء من المسئولية المدنية على الفعل الضيار(^) وهي خارجة عن نطاق دراستنا فهل يعني ذلك تسليما وقبولا من المشرع الإماراتي لتطبيقه على الإعفاء من المسئولية العقدية دون التقصيرية على

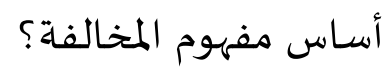
غالبية الفقه يتجه لقبول شروط الإعفاء او الحد من المسئولية بالنسبة للعمل الطبي، وذلك استناداً لحق أطراف العلاقة التعاقدية على ذلك، على أن لا يتعدى حجم الخطأ الطبي، للخطأ 
الجسيم أو الذي ينتج عن حالة غش، وقد قيل في تبرير عدم صحة الإعفاء من المسئولية الناشئة عن فعل متعمد لأن ذلك يتنافى مع الأحكام العامة في أحكام الالتزام والتي تمنع إنشاء التزام المدني قائم على شرط إرادي إذا شـاء نفذه وإن لم يشأ لم ينفذه(9). إن التعليق على إرادة المدين أمر لم يقبله المشرع المصري لصحة تنفيذ الالتزامات فقد جاء نص المادة VTr من القانون المدني المصري أنه(لا يكون الالتزام قائماً إذا علق على شرط واقف يجعل وجود الالتزام متوقفا على محض إرادة الملتزم(.).) ونتفق مع ضرورة عدم جواز إعفاء الطبيب من المسئولية العقدية الناشئة عن فعل متعمد وأظن أن هذه الحالة تتناسب مع الفعل الضار كمصدر للالتزام أكثر من كونها تمثل إخلالا عقدياً.

ينبغي أن نشير لأن هناك كثيراً من المناشدات التي صرح بها قانونيو في دولة الإمارات العربية مبناها بأنه: أن المسئولية الطبية التي يتحملها المستشفى أو الطبيب تعتبر غير رادعة وأشـارت إلى أن أول ما تلزم باه بعض المستشفيات المرضى قبل العملية هو التوقيع على ورقة تُخلي المستشفى من خلالها مسئوليته، الأمر الذي يضطرهم لتوقيعها خاصة أن المريض المتألم عادة يكون كالغريق الذي يحتاج إلى قشـة يتعلق بها ليتخلص من الألم (وأن هذه الورقة يجب إلزام المستشفيات بإلغائها أو عدم استعمالها مع جميع الحالات أو السماح لذوي المريض بالتوقيع عليها(1)") . ينبغي الإشارة قبل الخوض في قبل قبول أو رفض فكرة إعفاء المستشفى من الخطأ الجسيم

$$
\text { للطبيب أن نصنف المستشفيات لنوعين : }
$$

- الأولي: وهي المستشفيات العامة الحكومياة، فهذه يكون الطبيب فيها بمنزلة موظف عام وليس له أي حرية في اختيار المرضى للعلاج، وعليه اعتبر أن خطأ الطبيب هنا لا يمكن تصنيفها بالخطأ الذي ينشئ مسئولية عقدية وبما أن موضهوع بحثنا يركز على الإعفاء أو الحد من المسئولية وهو غير جائز إلا في نطاق المسئولية العقدية فلابد من دراسة الأمر في إطار المستشفى الخاص من حيث إمكانية إعفاؤه كمدين من أشخاص

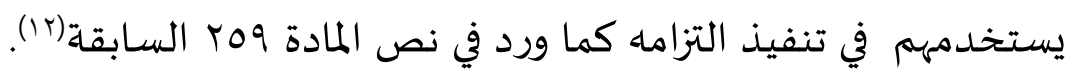


- الثانياة: وهي التعاقد مع مستشفى خاص لإجراء مثلا عملية جراحية فقد وجدت أن العقد يقسم مسئولية المستشفى تجاه خطأ الطبيب لعدد من التقسيمات: أ. وهي حالة عدم وجود رقابة مطلقة أو توجياء إداري بين المستشفى الخاص والأخصائي فهنا تكون علاقة التبعية غير متوافرة وبالتالي لا يسأل المستشفى عن عمل الأطباء ويقتصر دور المستشفى على حجزغرفة لإجراء العملية الجراحية(rا). ب. حالة الاتفاق بين المستشفى والمريض لإجراء تدخل جراحي تلتزم باه المستشفى بالعناية الطبية عن طريق تكليف أحد أطبائها العاملين والمساعدين لها فإذا نتجت أي أخطاء طبية من هؤلاء فيسأل المستشفى عنها باعتبار توافر المسئولية العقدية التي نتجت عقب تنفيذها لعقد أبرم بين الأخصائي والمريض و الذي تولد عنه علاقة تعاقدية أخرى بين المريض والمستشـى. ت. قد يكون الخطأ الطبي مصدره مسـاعدوالطبيب مثل طبيب التخدير أو قسم الأشعة، فهنا يقرر الفقاه التمييز بين حالتي اصطحاب الأخصائي لهم للعمل تحت إشراقه فهنا يكون الطبيب مسئولا عن أخطائهم ولا يتحمل المستشفى شيئا عنهما؛ والعكس صحيح فإذا كان تعيين الكوادر الطبية تم عن طريق صفتهم كعاملين في المستشفى فإن المستشفى تسأل عن أعمالهم دون الطبيب الأخصائي . وقد نادى البعض منعا لتشتيت المسئولية بين المستشفى والأخصائي في مواجهة الطبيب لضرورة تحملهما المسئولية على سبيل التضيامن تسهيلا للمضرورووهو المريض .(ع).. يرى الباحث أن قبول شرط الإعفاء المرضى من المسئولية لا يبدو عادلا في حق المستشفى إلا في إطار الفقرة (أ) التي بموجبها يكون دور المستشفى كمرفق صسي يقتصر على حجز غرفة للمريض لأجل قسط الراحة للمريض، فهنا يتصور عدم المانع من إبرام عقد طبي يرد باه شرط يعفيها من أي مسئولية نتجت عن خطأ الطبيب لكن الأمر لا يبدو بهذه البساطة عند التطبيق العملي فأدوار المستشفيات الخاصة الآن ومع تطور سبل العلاج وزيادة الإمكانات المادية فإنها تضاعفت ولم تعد قاصرة على حجز غرفة للمريض فحسب ؛مما يوسع من فرص زيادة تحملها للمسئولية العقدية مع تحمل الطبيب الأخصائي لذات المسئولية في الدعوى الواحدة. 
وأخلص من هذه النقطة، أن إعفاء المدين من المسئولية العقدية إذا كان على المتبوع دون التابع أجده لا يتوافق مع منظور العدالة لسببين أساسين وهما: أ. أن الغرض الأساس من إقرار مسئولية المتبوع هو تعويض الغير عن الضرر الذي أصابه

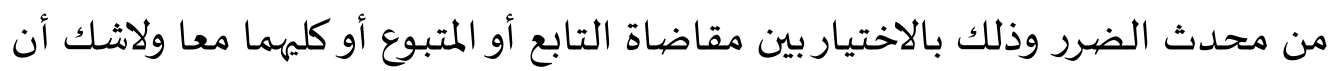
علاقة التبعية متوافرة بين المستشفى الخاص والطبيب الأخصائي مما لا يسوغ في هذا المقام حرمان المريض من مقاضاة أيهما أو كليهما (فصاحب المستشفى متبوع لأطبائه الذين يعملون لحسابه في المستشفى حتى ولو لم يكن هو نفسها طبيبا(10).

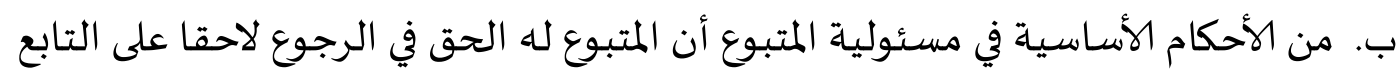
بما دفعاه من تعويض لشخص المضرور بما يعني حق المستشفى بالرجوع على الأخصائي بما تم تعويضها للمريض نتيجة الخطأ الجسيم أو حتى لو كان متعمد|(17).

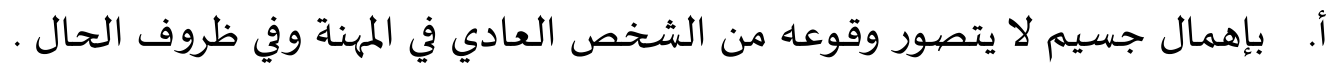
نخلص من كل ذلك ان المشرع الإماراتي فلم يورد تنظيما خاصا بالشروط المعفية أو التي تحد من المسئولية في القواعد العامة بموجب قانون المعاملات المدنيه الحالي لسنة 1910مام وبالإضافة لخلو قانون المسئولية الطبية الجديد لسنة 17 . من من أي إشارة تنظم هذه المسألة

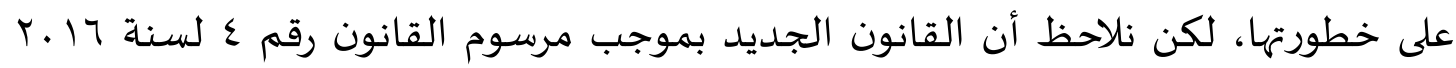

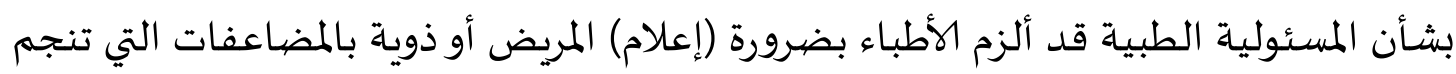
عن التشخيص أو العلاج الطبي أو التدخل الجراحي قبل بدء تطبيقه ورصدها . ونرى أن هذا التطبيقة لايدخل ضمن مفهوم الإعفاء أو الحد من المسئولية، إذ ليس الغرض

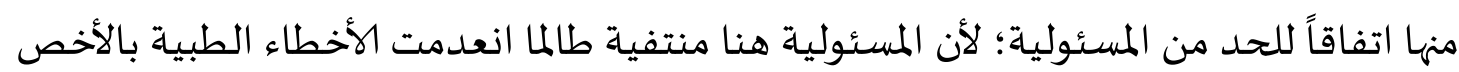
الجسيمة منها. غير أن الأمر يمثل مسلكاً حسناً في التعديل الجديد، حيث أن القانون الملغي لسنة م . .ب م كان يلزم الأطباء برصد المضاعفات الناجمةعن العلاج الطبي أو الجراحي والمبادرة لعلاجها، لكن لم لم

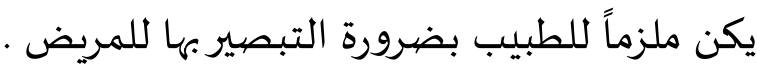
وأعتقد أن الذي حدا بالكثيرين حتى الممارسين للعمل القانوني للمطالبة بإلغاء القرارات أو هورد الاشتراطات المعفية للمسئولية الطبية والتي تقدمها المستشفيات هو عدم توافر الحماية القانونية اللازمة للمريض من خلال ما سنراه من أسانيد وهي: 
ا-أن توقيت منح هذه الوثائق الطبية والتي اعتبرها بمنزلة عقد طبي يتم تقديمها في وقت لا يرغب فيه المريض عادة بقراءة كل ما ورد فيها من بنود وذلك بسبب الحاجة الماسة للشفاء بسرعة ومقابلة الأطباء أو أحيانا إجراء عمليات جراحية مستعجلة لا تمكن في الغالب المريض من قراءة تلك القرارات فيوقع دون قراءاتها . 1. ولإنصاف فإن تكدس المرضى بالمستشفيات ورغبة الأطباء والكوادر الطبية في علاج المرضى فهو لا يتيح الفرصة الكافية لكي تتثبت المستشفيات من قدرة المريض على استيعاب ما ورد في هذه البنود والتي تأتي في غالبها معفية أو تحد من مسئولية المستشفى والطبيب عن أي أخطاء علاجية تلحق بالمريض .

مما يجعلنا نناشـد المشرع الإماراتي بتقنين شروط الإعفاء أو الحد من المسئولية ضمن أحكام قانون المسئولية الطبية النافذ. بحيث تلزم المستشفيات بصياغاة بنودها بشكل يسمح بالإطلاع على تلك البنود بلغة سهلة وغير معقده، بالإضيافة لضرورة خلو هذه الاشتراطات من البنود المعفية إعفاءً كاملاً من أية مسئولية ؛ باستثناء كما ذكرنا حالتي التجارب الطبية أو الشخص

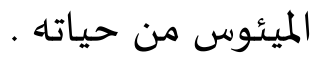

$$
\text { المطلب الثاني }
$$

\section{شرط الإعفاء أو الحد من المسئولية الطبية بين القبول والرفض}

واقع الأمر فإن الفقه القانوني الحديث ظل منقسما في إطار قبول أو رفض شروط

$$
\text { الإعفاء أو الحد من المسئولية الطبية لعدد من الاتجاهات المختلفة . }
$$

فالاتجاه الأول(IV) وهو إتجاه عام في المسئولية العقدية قضى بقبول البنود النافية

كلياً أو جزئياً للمسئولية العقدية، وذلك باعتبار أن أطراف العقد لهم الحرية التعاقدية الكاملة لتنظيم تلك الشروط المعفية طالما لم تخالف قواعد النظام العام والآداب. وقد قصر تطبيق البنود المعفية كليا أو جزئيا عن المسئولية العقدية على العقود التي تتضمن عنصرا للمخاطرة أو المجازفة .

أما الاتجاه الثاني(1) فهو إتجاه خاص بالمسئولية الطبية في الفقه فقد اعتبر أن اشتراط المستشفيات قبول المريض لما تشمل عليه الوثيقة الطبية التي تقدم للمريض ما هي إلا ورقة للضغط فيها على إرادة المريض والذي لا يجد العلاج إلا إذا رضخ على اتفاق الإعفاء من 
المسئولية وقد اعتبر ذلك من باب الاستغلال لحاجة المرضى للعلاج ولا يكون أمام المريض سوى أمرين وهما القبول أو الرفض لتلك الوثيقة .

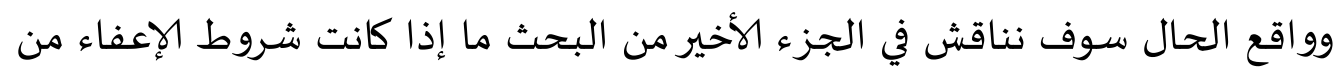

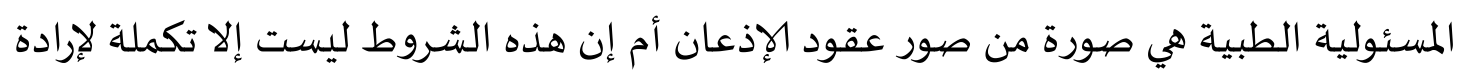
العاقدين الحرة الخالية من الإذعان.

ويرى الاتجاه الفقهي الأخير ضرورة اعتبار الشروط المعفية من المسئولية الطبية ما هي إلا شروط، والقصد منها تخفيف المسئولية وليس الإعفاء منها نهائيا ويقترح تفعيل الاتفاقات المححدة أو المخففة للمسئولية بديلا عن الاتفاقات المعفية عن أثر العلاج .

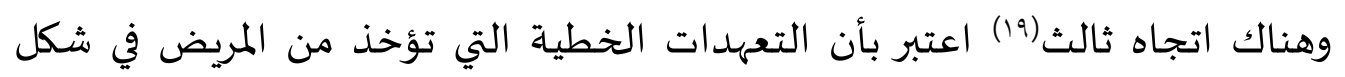

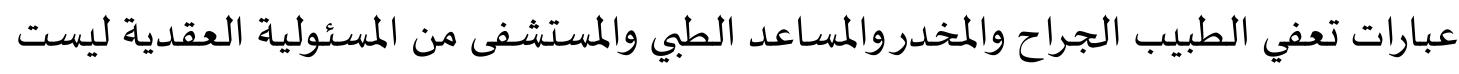
في حقيقها إلا دليل كتابي لإثبات حصول التبصير للمعلومات التي تهم المريض فإذإ تضيمنت

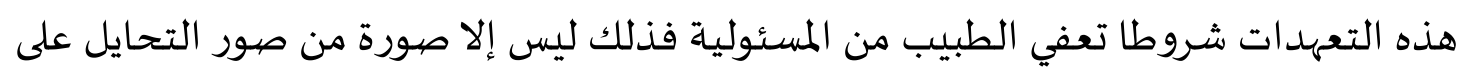
المرضى بالأخص المرضى الذين لا يحسنون القراءة والكتابة .

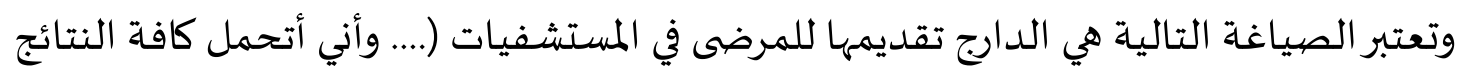
والمضاعفات أثناء إجراء العملية وبعدها، وهذا إقرار كامل أوقعه بكامل حريتي وإرادتي بعد

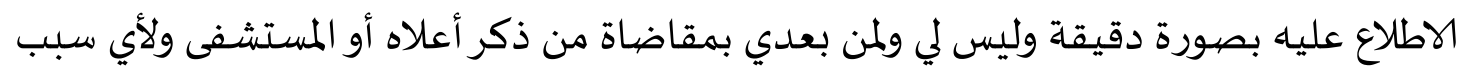
كان لإفهامي الكامل من قبل الجميع بخطورة العملية واختلاطاتها وعليه وقعت). ويناشد الباحث بضرورة تطبيق شروط الحد من المسئولية الطبية بدلا عن الإعفاء منها كلية فالحد من المسئولية الطبية يمكن تطبيقه في مجال جعل التزام الطبيب يبذل عناية وهو التزام يفرضه المشرع عادة بدلا من جعل الالتزام تحقيق نتيجة، مع ملاحظة أن بعض الالتزامات التي تقع على الطبيب لابد فهيا من تحقق النتيجة وليس فقط بذل الحرص والعناية اللازمتين

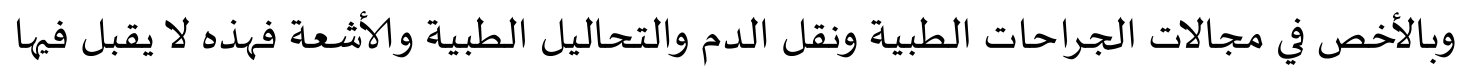

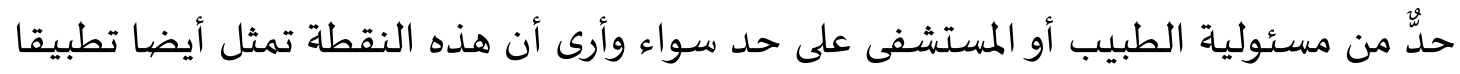
مغايرا لقواعد المعاملات المدنية بالأخص التشريعات التي قبلت الإعفاء أو الحد من المسئولية كاتفاقات معدلة للمسئولية. 


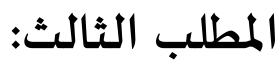

\section{البنود التي تحد أو تعفي من المسئولية الطبية في التشريع الأنجليزي}

تختلف القواعد المنظمة لتحمل عواقب العمل الطبي بين النظم القانونية في تشريعات النظم ذات الطابع اللاتيني و والتشريعات الإنجلوسكسونية، وبعبارة أخرى فإن الملاحظ أن بأن التشريعات الغربية دائما ما تعلي من شأن المسئولية الأخلاقية وتجعلها مسئولية قانونية موجبة

$$
\text { للمساءلة وقتما توافر لها السند القانوني المطلوب. }
$$

ولعل من أهم سمات التشريعات الغربية الصحية نظام الإفصاح عن الخطأ الطبي

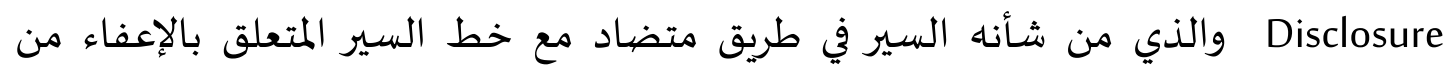

$$
\text { المسئولية الطبية. }
$$

فيرى البعض أن الارتباط وثيق الصلة بين الثقافة الطبية والخوف من المسئولية القانونية حيث يعمد الأطباء دائما لعدم مناقشة المرضى عنهما بشكل صريح حرصا على مصالح شركات التأمين التي تطالههم بعدم مناقشة الأمور المالية مع المرضى .(r.) ولا شك أن اتجاه التشريعات الأنجلوسكسونية لإقرار مسئولية الطبيب عبر ما يسمى بالإفصاح المباح عن الخطأ الطبي حقق فوائد عديدة لا تخطئها عين فهي تساعد المريض في اتخاذ القرارات الخاص لوضعاه وبالإضافة لأن المؤسسات الصحية التي تناقش أخطاءها تكون قادرة على معرفة أسباب الأخطاء الطبية ومن ثم تفاديها مستقبلا . بل إن الدراسات أوضحت أن مبدأ الإفصاح يعتبر ذا فائدة كبيرة من حيث تحقيق الأباح وتقليل الخسائر المادية فعند ما يتم الإفصاح عن خطأ الطبيب في وقت مبكر فإن ذلك من شأنها تقليل تكاليف التقاضي وحجم المال المدفوع كتعويض حيث أوضحت تجربة المراكز الطبية التابعة لجامعة متشجان أن عدد المطالبات القضائية وحجم التعويضات قد انخفض بشكل واضح

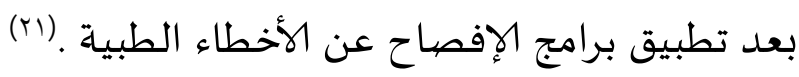
وبالتأكيد نفتقرفي تشريعاتنا العربية بصورة مجملة لهذا النوع من الالتزام بالإفصاح عن الخطأ بالرغم من القواعد التي نظمت في خصوص الالتزام بالتبصير، وربما يكون ذلك مجالاً آخر جديد للبحث القانوني من الممكن أن يؤتي ثماره لو تم دراسته بصهورة متعمقة. 
وبالرجوع إلى جانب الإعفاء أو الحد من المسئولية في التشريع الأنجلوسكسوني وجدنا أن جانباً

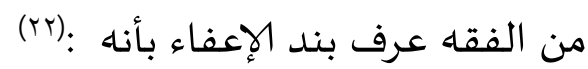
(حكم الإعفاء هو الحكم الذي يهدف إلى استبعاد مسئولية الأطراف بسبب مخالفة أو حصر

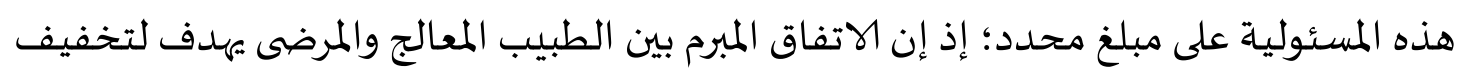
مسئولية الاخصائي عن الإهمال) كما عرف جانب من الفقه اتفاق البراءة من التعويض:(rr) (بأنه اتفاق بالإبراء بين الطبيب الإهمات المعالج والمرضى يهدف لتخفيف مسئولية الأخصائي عن الإهمال) بعض أحكام القضاء في النظام الأنجلوسكسوني مالت في إتجاه لضرورة إيقاف المستشفيات الإهمات عن استخدام نماذج اتفاق التبرئة (Exculpatory agreement) لأن هذه الاتفاقات باطلة وقد أوصت بضرورة عدم استخداهها إلا في إطار إجراءات التجارب الطبية والتي تتطلب معيارا مختلفا بحكم طبيعتها وقد استندت تلك المصادر على ما جاء في قضية Cudnik لميث عرفت المحكمة اتفاقات التبرئة بأها: اتفاقية تعفي الشخص من المسئولية في حالة تصرفه بحسن نية، واتفاقات التبرئة في السياق الطبي تعتبر باطلة بشكل عام حيث جاء في تلك القضية أن كودنيك خضع لعلاج إشعاعي في مارس وأبريل 1910 عقب خضوعة لعملية جراحية لإصابته بسرطان البروستاتا وقبل خضوعاه للعملية قام بالتوقيع على وثيقة موافقة تتضمن على ما يأتي:(ro) (كما قام الطبيب بشرح كافة الاحتمالات

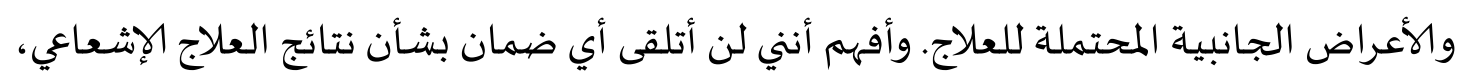
وبعد فهم ما سبق فإنني بموجب هذه الوثيقة أبرئ الأطباء والموظفين في قسم علاج إن الأورام

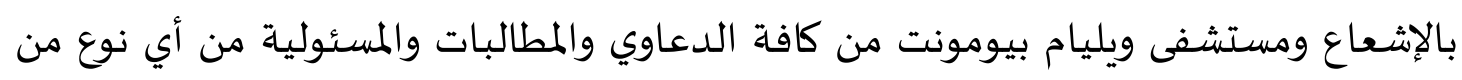
جانبي أو من جانب ورثني) أتفق مع مسعى المشرع الإنجليزي في ضرورة إبطال شروط الإعفاء من المسئولية عن الإهمال

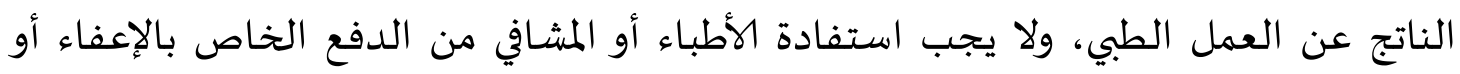

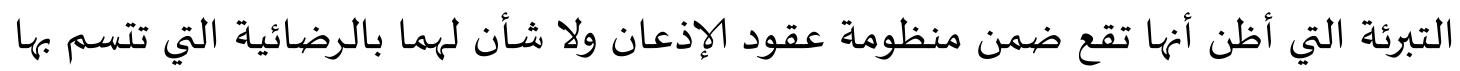
العقود عادة.

لكن مع ذلك يظل مسعى المشرع لقبول اتفاقات الإعفاء من المسئولية في إطار ضيق وهو مجال إجراء التجارب الطبية؛ لاسيما أن التعديل الجديد في قانون المسئولية الطبية الإماراتي جعل 
(إرادة المريض) هي الأساس في قبول عمل هذه التجارب الطبية ؛ إضافة إلى الموافقة من الجهات

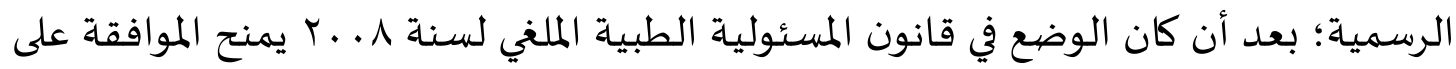
التجارب الطبية بناءً على ترخيص من الجهات الرسمية؛؛ دون أي اعتبار لـ(إرادة المريض)؛ فنص

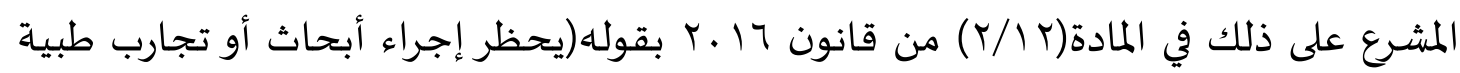
على الإنسان إلا بعد موافقته والحصول على تصريح كتابي بذلك من الجهة التي تحددها اللائحة التنفيذية وتبعاً للشروط التي تقررها تلك اللائحةة) ولعل الأمرسانحة لقبول الإعفاء من المسئولية؛ طالما يتوقع حصول أضرار أوعدم تحقق النتيجة

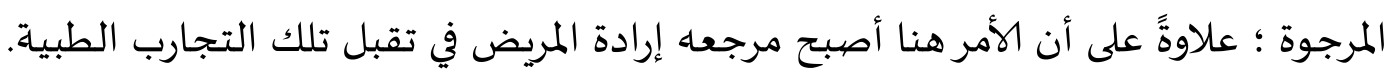

\section{المبحث الثاني}

\section{تشـيد المسئولية الطبية ومدى مقاربة الإعفاء أو الحد من المسئولية الطبية}

\section{لعقود الإذعان}

أقوم باستعراض موضوعين رئيسين في هذا المبحث الثاني، وأستعرضهما في مطلبين منفصلين، يتناول المطلب الأول البنود التي تشدد على المسئولية الطبية في القانون الإماراتي،

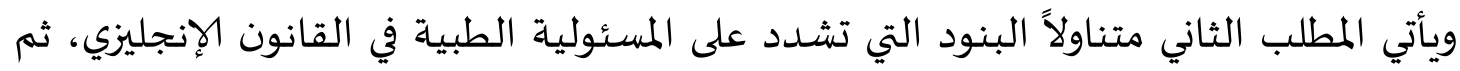
نختتم المطلب الثالث بموضوع المقاربة بين الإعفاء والحد من المسئولية الطبية وعقود الإذعان

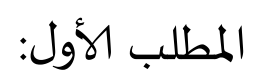

البنود التي تشدد من المسئولية الطبية في القانون الإماراتي

رأينا فيما سبق أنه لا يجوز إعفاء المدين أو الحد منها في إطار الفعل الضار، وإذا إنتهينا لتلك

$$
\text { النتيجة ؛ فهل يمكن }
$$

التشديد في مسئولية الطبيب كمدين، وذلك في إطار المسئولية التقصيرية والعقدية على حد

$$
\text { سواء؟ }
$$

وما هي صور التشدد في المسئولية الطبية؟ 
وهل يجوز الاتفاق مسبقا على تحديد قيمة تعويضية في حال فشل إجراء عملية جراحية تزيد

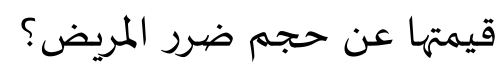
واقع الأمر فإن القانون الإماراتي قد قَصَّربط بطلان الإعفاء أو الحد من المسئولية على الفعل الضار، وهذا لا يشمل تشديد مسئولية المدين على الفعل الضار كمصدر للالتزام منشئ للمسئولية التقصيرية. وعليه بالنظر لراي البعض من (rr) الفقه الحديث نجده قد قبل تشديد مسئولية المدين (الطبيب) في عدة صور مختلفة وذلك استنادا للقواعد العامة التي وردت في القانون المدني المصري بنص المادة I/TIV والتي أجاز فيها المشرع الاتفاق على تشديد مسئولية المدين، ويكون

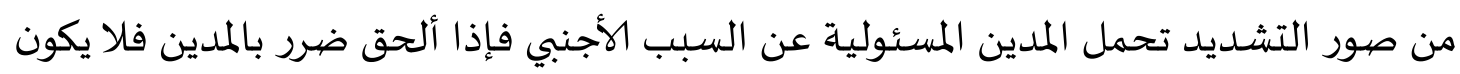
أمام القضاء إلا الاستناد عليه في الأحكام وذلك دون التحقق من بقية أركان المسئولية التقصيرية

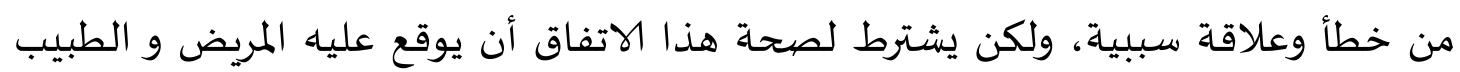

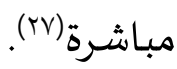
وقد عبر جانبّ من الفقه بمشروعية تشديد مسئولية المدين؛ استنادا لشرط عدم مخالفة النظام العام، والتي لا تتعارض فكرتها هنا مع تحمل المميض بإرادته للمسئولية ولو لم يرتكب لمبك خطأ(r). ويرى البعض أنه امتثالا لقاعدة (من يملك الأكثر يملك الأقل)، فإنه طالما يتحمل المدين مسئولية السبب الأجنبي فإنه يملك أيضا تشديد المسئولية عليه عبر اتفاق الطرفين (المريض

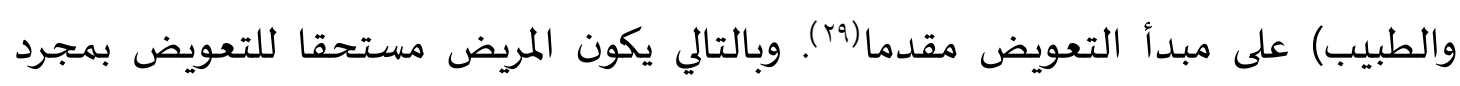
حصول الضرر دون أي مراعاة لبقية أركان المسئولية العقدية أو التقصيرية والتي تستلزم الخطأ أو الإضراروعلاقة السببية.

ومع تسليمنا صحة هذا النوع من التعويض الاتفاقي والذي نرى أنه صورة مشابهة لفكرتي التأمين ضد المسئولية أو فكرة الشرط الجزائي؛ ولعل هذا التمثيل قائم على فكرة تماثل (درجة التهائ الاحتمال) في حصول خطر التأمين أو احتمال حصول الشرط فكلاهما لا يقعان إلا في الأمور المحتملة وليست المؤكدة أو المستحيلة . 
ولكن الباحث يجد نفسه مرجحا لفكرة الشرط الجزائي باعتبار أن عقد التأمين هذا لا يتناسب تطبيقه بالنسبة لعلاقة المريض والطبيب فالمؤمن دائما لابد أن يكون شركة تأمين أو جمعية تعاونياة بمعنى شخصية معنوية ذات ترخيص مسبق لتقديم هذا النوع من الخدمات .

ونجد المشرع الإماراتي نص على أنه :

ا. يجوز للمتعاقدين أن يحددا مقدما قيمة التعويض بالنص عليها في العقد أو في اتفاق

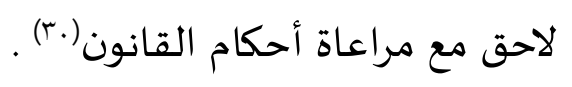

r. ويجوز للقاضي في جميع الأحوال بناء على طلب أحد الطرفين أن يعدل في هذا الاتفاق

$$
\text { مما يجعل التقدير مساويا للضرر، ويقع باطلا كل اتفاق يخالف ذلك . }
$$

عرف البعض (rاr) من الفقه الشرط الجزائي بأنها (اتفاق على تقدير التعويض سابق على وقوع

الضرر يستحقه الدائن عند إخلال المدين بتنفيذ التزام ووقوع الضرر بسبب هذا الإخلال). وتعتبر مسألة موائمة حجم الضرر مع التعويض الاتفاقي المطلوب في حال حصيول ضرر للمريض أمراً بالغ التعقيد عند النظر لتوجهات فقهية وتشريعية اختلفت في مجملها لتكييف هذه

ووجدت ان التشريع الإماراتي قد حسم المسألة بضرورة مراعاة حق الدائن والمدين عند تنظيماه للشرط الجزائي فيكون للمدين (الطبيب) في حالة حصيول ضرر على المريض الذي استحق باه الشرط الجزائي، وهو التعويض أن يسمح له بطلب إنقاص حجم التعويض الاتفاقي بما يتناسب

$$
\text { مع الضرر الفعلي. }
$$

بينما هناك تشريعات أخرى أخذت بتطبيق الشرط الجزائي دون أن يترك المجال للمدين بطلب إنقاص حجم التعويض المالي للضرر وقد طبقتها القوانين الغربية على رأسها القانون المدني الفرنسي والذي نص على:

إذا ذكر في الاتفاق أن الطرف الذي يقصر في تنفيذ التزامه يدفع مبلغا معينا من النقود على سبيل التعويض؛ فلا يجوز أن يعطى تعويض الطرف الآخر مبلغا أكثر أو أقل (rr). 


\section{المطلب الثاني}

\section{البنود التي تشـدد على المسئولية الطبية في القانون الإنجليزي}

يرى البعض بأن الفقه الأنجلوسكسوني يجده قد سمح بقبول تشديد المسئولية المدنية على الطبيب عبر إجراء نظام التعويضات Compensation ذلك الموقف على ما أفرزته التجارب العملية بقبول دفع تعويضات من المستشفى أو عن طريق رئيس الطاقم الطبي بسبب المسئولية الناتجة عن تنفيذ الواجبات.

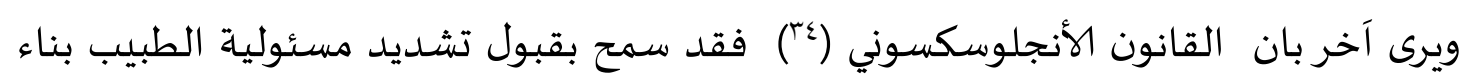

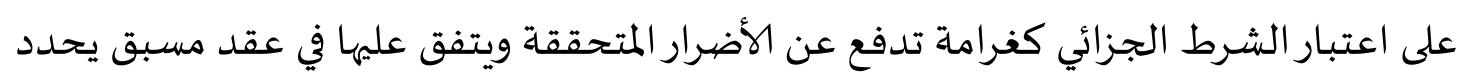

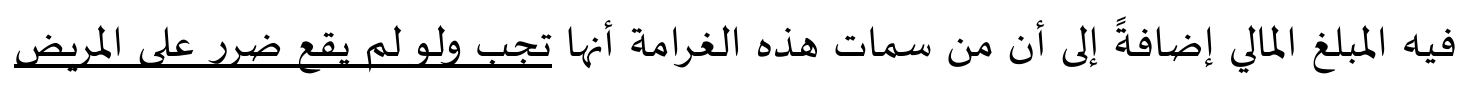

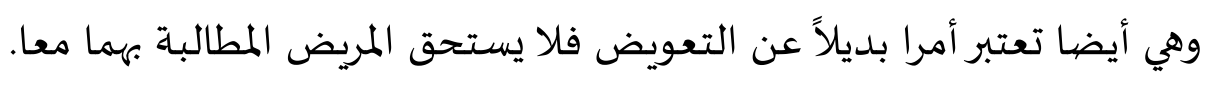

ومن أهم ملاحظاتنا على ما ورد من أحكام متباينة في تطبيقات تشديد المسئولية على المدين، فإن الباحث توصل للنقاط الآتية: لاحظت أن المشرع الأنجلوسكسوني لم يحدد مستوى الخطأ من حيث الدرجة في الجسامة أو الو الماتها:

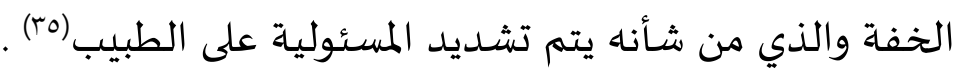
وبالنظر للقانون الجديد الاتحادي بشأن المسئولية الطبية لسنة 17 ـب ؛ فوجدنا من خلال

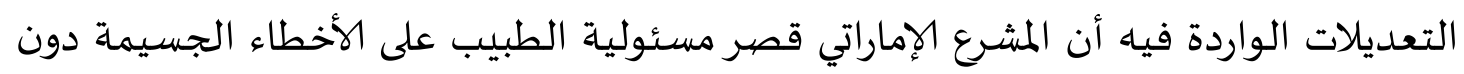
غيرها ؛ وبهذا يكون الباب قد أقفل أمام اجتهاد الفقة والقضاء والذي وجدنا أنسا أن (الأخير) من خلال البحث تضاربت بعض أحكامه في هذا الشأن، حيث اعتمدت المحكمة الاتحادية العليا

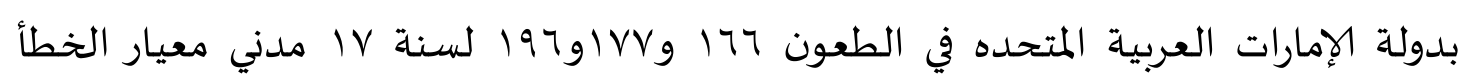

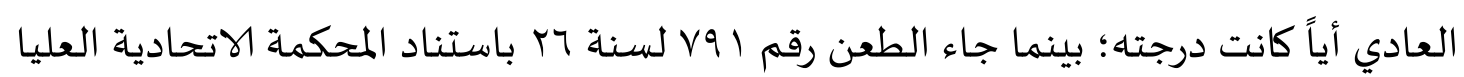
لخطأ الطبي ولو كان يسيراً . حيث نص المشرع الإماراتي بشكل جلي بالمادة 7 من القانون الجديد بقوله(الخطأ الطبي هو ما يرتكبه مزاول المهنة نتيجة أي من الأسباب الآتية:

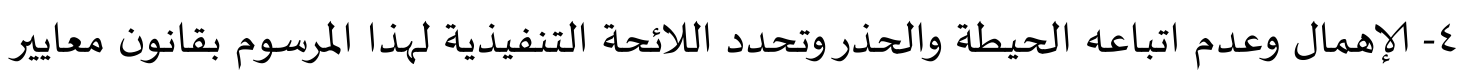

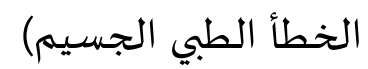


كما نص بالمادة عr من نفس القانون بقوله (... وفي جميع الأحوال لايجوز التحقيق مع مزاولي

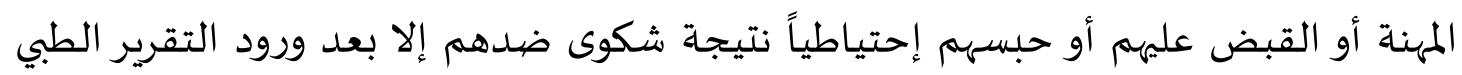

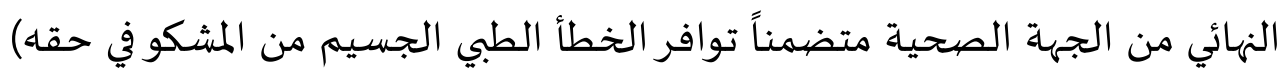

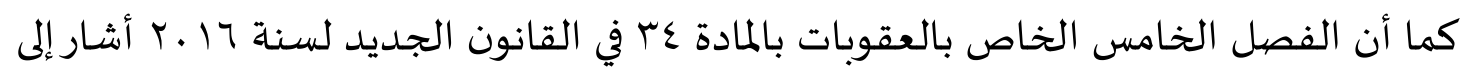
معيار درجة الخطأ الجسيم الموجب لإيقاع العقوبات على الطبيب بقولة (يعاقب بالحبس مدة

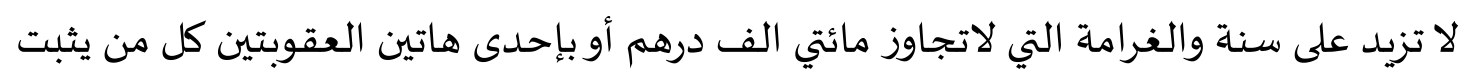
ارتكابة خطأ طبياً جسيماً على النحو الوارد في هذا المرسوم بقانون...)

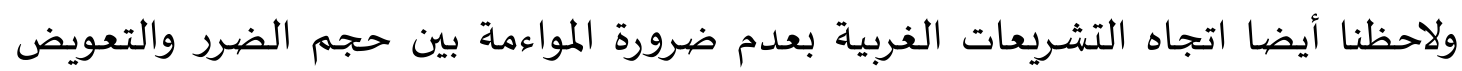
بالأخص إذا فاق التعويض الاتفاق حجم الضرر وهذا ما لا نرجحاه عند إقرار تشديد المسئولية الطبية على الطبيب أو المستشفى لسببين أساسين: - السبب الأول: وهو يتصل باعتبار قانوني محض وهو أن إقرار التعويض بما يفوق حجم اسلئ الضرر فيه هدم مباشر لتطبيق الإثراء بلا سبب كمصدر من مصادر الالتزام في القانون المدني. - - السبب الثاني: لا يجب إعمال تشديد المسئولية الطبية على ذلك النحو المتشدد باعتبار

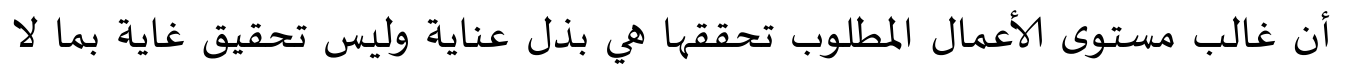
يتناسب البتة مع التشديد. ونختم قولنا بأن الباحث أيضا لا يتفق مع تشديد المسئولية الطبية بغير ضرر لأن في ذلك

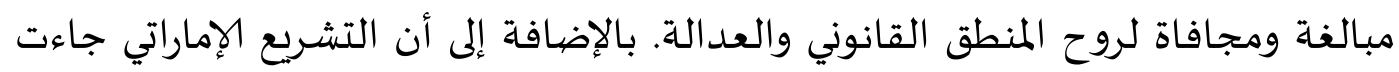
أحكامه في خصوص المسئولية التقصيرية (Tort Liability) متأثره بأحكام الشريعة

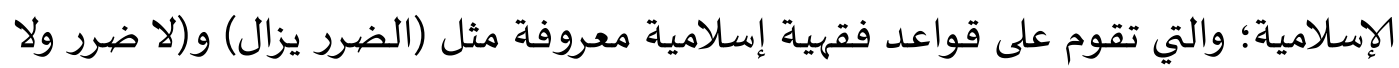
ضرار) فلا مسئولية بغير ضرر. 


\section{المطلب الثالث:}

مدى مقاربة الإعفاء أو الحد من المسئولية الطبية لشروط عقود الإذعان.

بعد أن انتهيت من عرض فكرة وتطبيقات الاتفاقات المنظمة للمسئولية الطبية، ارتأيت أنه لابد من ضرورة دراسة العقد الطبي بما حوى من شروط أو بنود معفيه أو تحد من مسئولية الطبيب والمستشفى. ومقاربته بالمقارنة مع طبيعة عقد الإذعان. فمن خلال البحث وجدت أن هناك تداخلا بائنا بين العقد الطبي والذي أصبح نموذجا معدا من لدن المستشفى وبين ما نسمياء بعقود الإذعان، ولذا سوف استعرض الآمر للتحقق من مدى أيلولة أو صيرورة تكييف العقد الطبي بأنه عقد إذعان مع بيان الشـواهد الفقهية والقانونية المتصلة بالموضيوع. ويستدعي الأمر هنا تقسيماه لفرعين استعرض الأول فياه ماهية عقد الإذعان وطبيعته وأركز في الفرع الثاني على المقارنة بين أحكام العقد الطبي وعقود .

\section{الفرع الأول}

\section{ماهية عقد الإذعان وتحديل طبيعته}

ظلل -لعقود طويلة- يتناول الفقهاء والمشرعون عقود الإذعان بأنها خروجٌ عن الأصل العام في إنشـاء العقود بإرادة العاقدين، وأن عقود الإذعان ليست إلا نمطا متميزا في كونه لا يقبل مناقشـة الطرف الآخر، والذي يسلم بما ورد فيـ من نصيوص وليس لهذا الطرف الآخر سوى القبول أو عدم إبرام العقد(rr). وقد شاع لزمن طويل أن عقود الإذعان تتمثل ظاهرة في عقود تحتكرها شركات كمرافق المياه والكهرباء، واللتان تقدمان خدماتها لمن يرضخ لشروطها أو يذعن لها، وإلا تعرض Standard Form of contract ${ }^{(r V)}$ للحرمان من تلك الخدمات ويطلق عليه في الفقـ الإنجليزي 
ونلاحظ أن التشريع الإماراتي لم ينص على تعريف واضح لماهية عقود الإذعان وقد اكتفيا

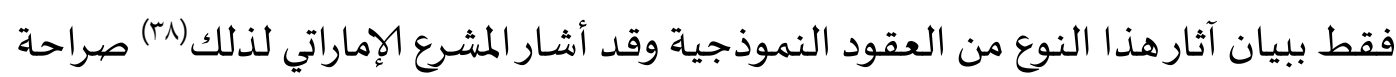
بأنه يرغب في التقليل من التعريفات في نصوص التقنينات ما أمكن.

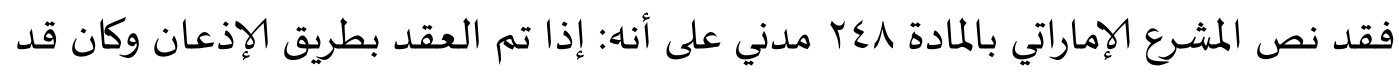
تضمن شروطا تعسفية جاز للقاضي أن يعدل هذه الشروط أو يعفي الطرف المذعن منها

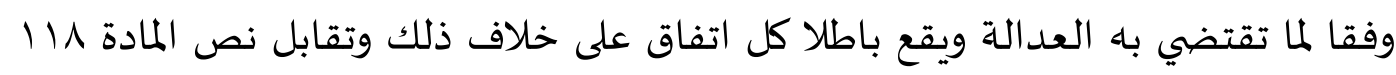

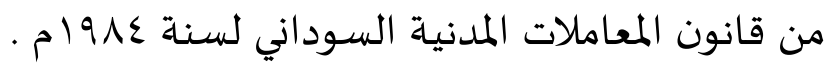

كما نصت المادة 0؟ إ من قانون المعاملات المدنية الإماراتي على أنه: (القبول في عقود الإذعان يقتصر على مجرد التسليم بشروط مقررة يضعها الموجب ولا يقبل مناقشته فيها)

وقد اعتبر المشرع الإماراتي(م+أن عقود الإذعان ماهي إلا ثمرة للتطور الاقتصادي، والذي

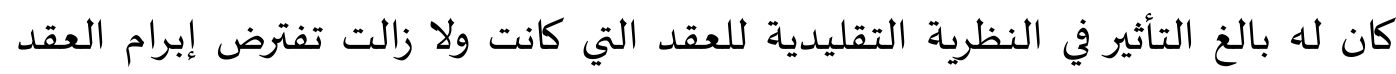

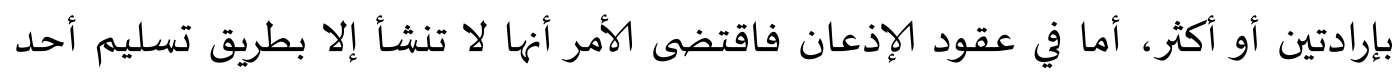

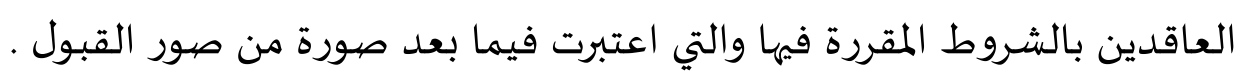
أما عن طبيعة عقود الإذعان فقد انقسم الفقه فيها إلى أكثر من اتجاه:

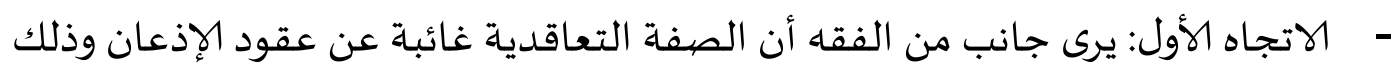
باعتبار عدم المساواة بين طرفي العقد حيث (يسيطر) الموجب بإرادته على إرادة المتعاقد الآخروالذي لا يملك سوى التسليم بالعقد وقد اعتبر عقد الإذعان بمنزلة مركز قانوني

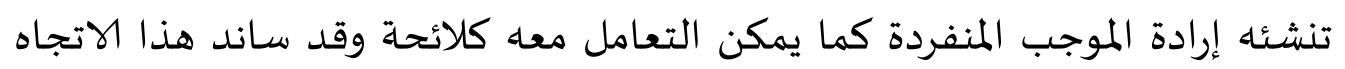

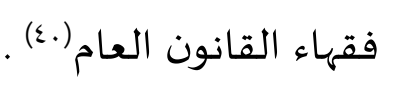

- الاتجاه الثاني: ويرى أنصاره ممن يعتبرون من فقهاء القانون المدني أن عقد الإذعان

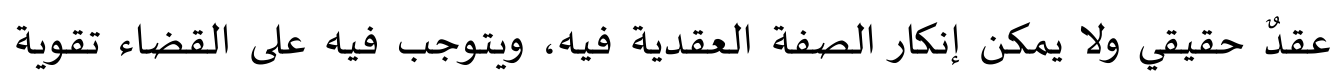
الجانب الضعيف وذلك بالوسيلة التشريعية عبر منح التشريع للقاضي سلطة تعديل 
العقد الذي ترد به شروطٌ تعسفية طالما ارتبط الأمر بعقود متصلة بمرافق عامة أو عقد عمل أو عقد تأمين(1)

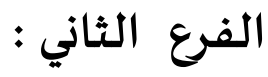

مدى مقاربة قواعد الإعفاء أو الحد من المسؤولية الطبية لشروط عقد الإذعان يحاول الباحث من خلال هذا المبحث بيان مدى الاقتراب أو ربما التطابق بين طبيعة عقود الإذعان والعقد الطبي، الذي كثرت فياه تطبيقات العقد النموذجي ببنود شروط الإعفاء أو الحدد من المسئولية.

في واقع الأمر فإن هذه الدراسة الموجزة يتطلب تحليلها وفقا للشروط الواجب توافرها

$$
\text { في عقود الإذعان وتتمثل هذه الشروط في الآتي : }
$$

- الشرط الأول: عقود الإذعان دائما تنصب على سلعة أوخدمة ضيرورية يحتكرها

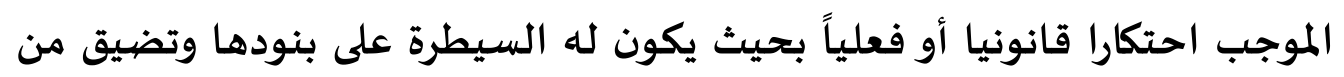

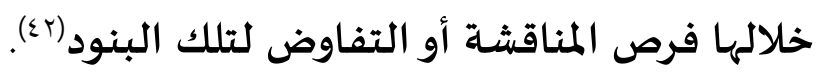
يجد الباحث أن العقد الطبي المكتوب أو الشفاهي ما هو إلا خدمة محتكرة احتكارا قانونيا

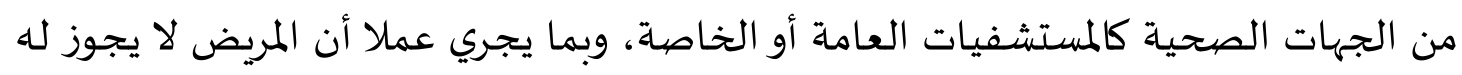

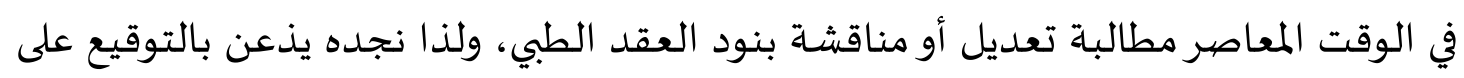

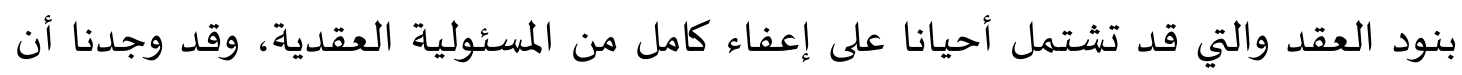
مذاهب الفقه اللاتيني والأنجلوسكسوني لم تقره البتة بشكل مطلق.

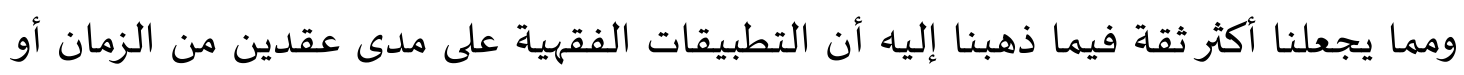

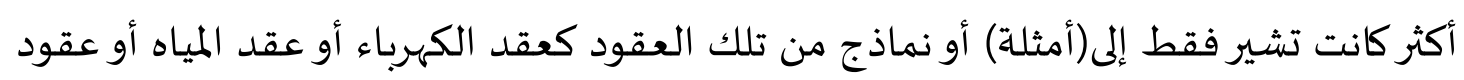
الاتصالات، وقد وردت فقط على سبيل المثال لا الحصر. فصحيح؛ أن هذه العقود لازمها الإذعان ولا زال، ولكن لاحظنا تغير صفتها من كونها محتكرة لا لا لهان

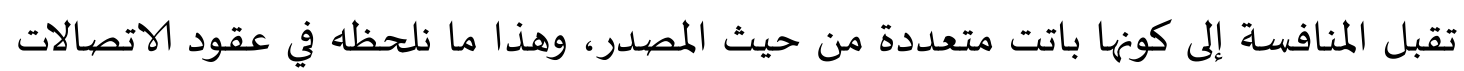
والتي تعددت في الدولة الواحدة، كما نلحظ توافر الطاقة البديلة في الوقت المعاصر (الطاقة

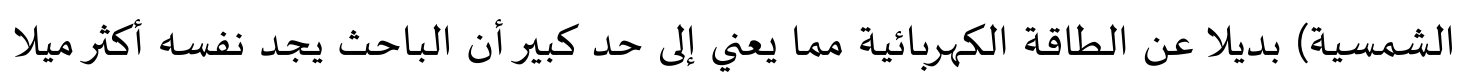


لقبول رأي البعض في اعتبار شروط عقد الإذعان متمثلة فقط في (شرط عدم قابلية العقد للتفاوض) فهو فيصل لحسم طبيعة هذه العقود عند البعض من الفقه(r؟). مما يعني إلى حد كبير هيمنة الدولة لإدارة وتنظيم هذه المرافق الصحياة، بل إنها نصت على واجبات متلقي الخدمة الطبية والتزامات المؤسسة الصحية مما يؤكد على صفة الاحتكار القانوني للعقد الطبي(๕)) بل إن بعض الأحكام القضيائية اعتبرت عدم الحصول على ترخيص مزاولة المهنة من اللجان المختصية يجعل عقد العمل باطلا(؛(؛).

الشرط الثاني: يتعلق العقد بسلع أو مرافق تعتبر من الضرورات بالنسبة للمستهلكين أو المنتفعين (乏) : (1)

Contract of وجدت أيضا أن الفقه والقضاء الإنجليزي قد ربط بين مفهومَي عقود الإذعان وشروط الإعفاء من المسئولية exemption clauses adhesion المستهلك بمقدم السلعة الضرورية وا لتي يتوجب فيها على المستهلك القبول والتسليم بالشروط الخاصة بالعقد وذلك دون أدنى مناقشة أو مفاوضية وإلا يفقد المتعامل حقه في الحصول على المنتج. ولاشك أنه إذا كانت السلع والمنتجات قد اكتسبت صفة أنها ضرورية، فما بال الأمر عند النظر لصحة الإنسان كمنتفع في المرفق الصحي، فهو بحاجة للحماية القانونية من العقد النموذجي

$$
\text { وهو العقد الطبي. }
$$

الشرط الثالث: توجيه عرض الانتفاع بالسلع أو الخدمات المرفقية للجمهور بشروط متماثلة

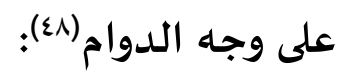
لعل من أهم المقاربات بين مفهوم عقود الإذعان والعقد الطبي ؛ كونه موجها للجمهور بشروط متماثلة؛ فليس هناك عقد طبي يختلف من مريض لآخر؛ فالأمر لا يعدو أن يكون عبارة عن نماذج مطبوعة لا تقبل المناقشة أو التعديل، وأحيانا يمكن أن يكون في صورة مبسطة كتذكرة أو إيصال دون قيد يعرض الشروط. وقد وسع الفقه الحديث في الوقت الحاضر من مفهوم عقد الإذعان بأنه يمكن أن يمتد لخدمات وكالات السفروالفنادق والمطاعم وغيرها من الخدمات التي توجـه للجمهور ولا تقبل المناقشـة(9). 
وقد أشرنا فيما سبق أن الفقه الإنجليزي قد قبل هذا النوع من عقود الإذعان وبالأخص عند تحديد أو استبعاد المسئولية عن صياغة العقود لكنه اشترط لصحتها الشروط الآتية: 1. إذا وافق الطرف الآخر للشروط يكن ملزما بها. r. لابد من كتابة هذه الشروط والعلم بها وقراءها فعليا ممن قدمت له؛ حتى تعتمد كشروط معفية للمسئولية(·) خلاصهة الأمر فإن الباحث يجد أن العقد الطبي بصورته الحديثة ما هو إلا عقد انطبق عليه شروط عقود الإذعان مما يجعلنا نناشـد بضرورة منح القضياة سلطة تعديل تلك العقود الطبية وبالأخص وقد كثرت فيها بالآونة الأخيرة بنود الإعفاء الهائي من المسئولية العقدية، أو محاولة إعفاء المستشفى عما يصدر من أخطاء طبية صادرة من أطباء يعملون في المستشفى. 


\section{الخـاتمـه:}

في ختــام هـــا البحــث توصــل الباحــث لجملــة مــن النتــائج والتوصــــات؛ وتتمثـل في الآتي:

\section{أولاًا النتائج:}

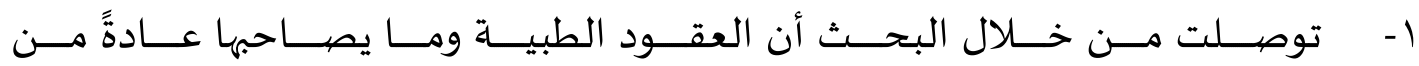

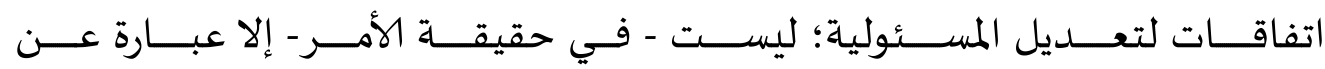

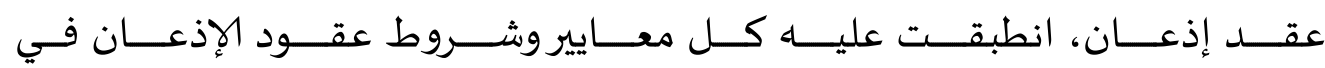
الفقهين اللاتيني والأنجلوسكسوني .

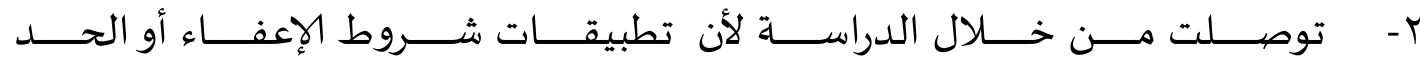

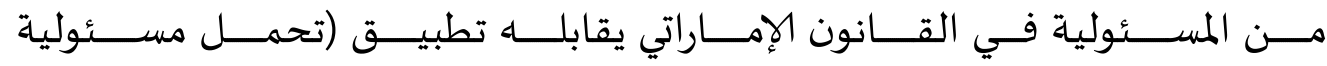

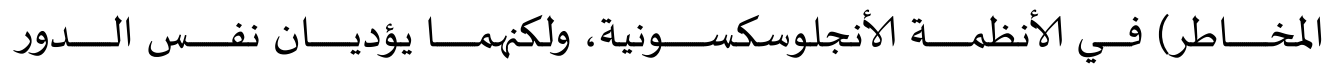
المناط باه وهو استبعاد مسئولية الطبيب (المدين) أو التخفيف منها.

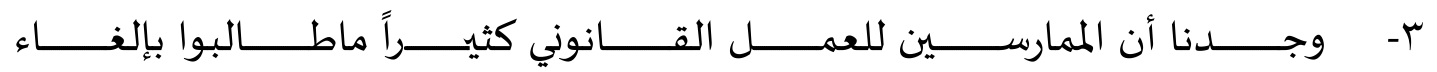

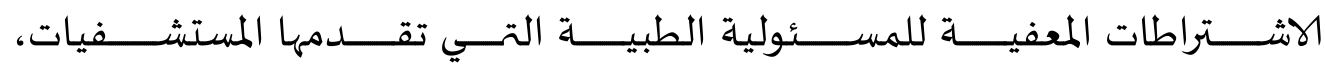

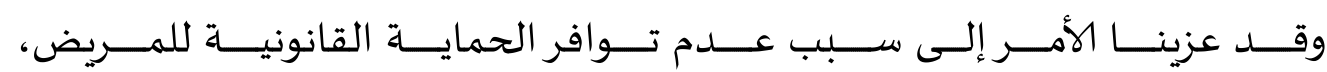

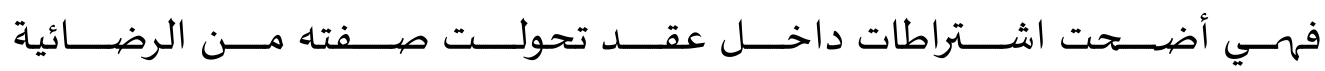
لصفة الإذعان . - لص

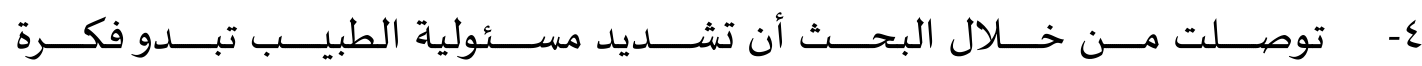

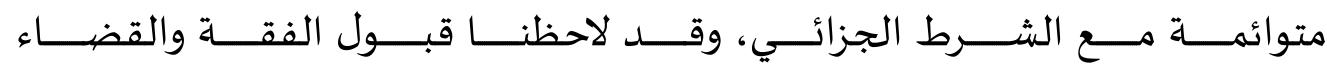
الإنجليــزي فكـــرة التعـــويض مقـــدماً، ولـــو لـــم يقـــع ضـــرر عالـى المـــريض، وهـــا مــا لا يمكــن تطبيقــة فـي التشـــريع الإمــاراتي، باعتبــار تـأثيرات الفقــة الإســـلامي والتهــي أسـاســهـا (لا ضــــرر ولا ضــــرار) وو(الضــــرر يـــزال). فــلا مسئولية إلا بتحقق الضرر. 
ثَانياً: التوصيات:

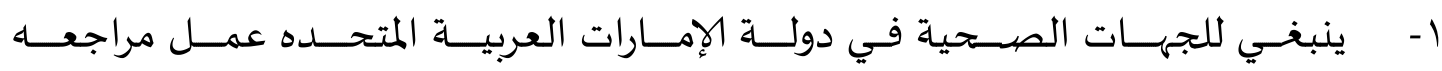

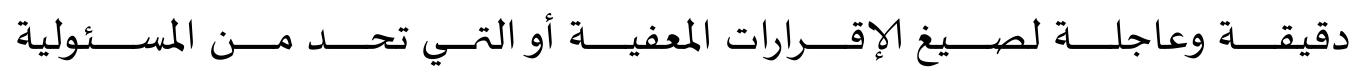

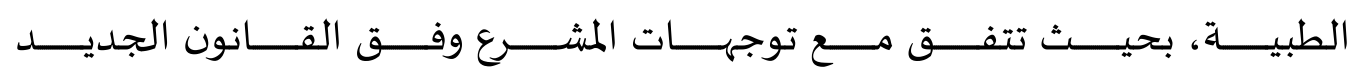

لسنة 1 . T.

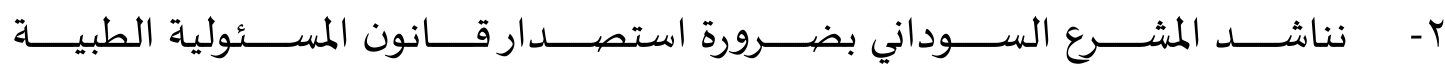

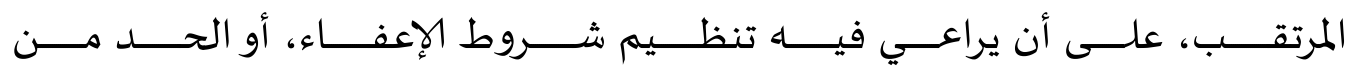
المسئولية أو تشديد المسئولية بين المريض والطبيب والمستشفى.

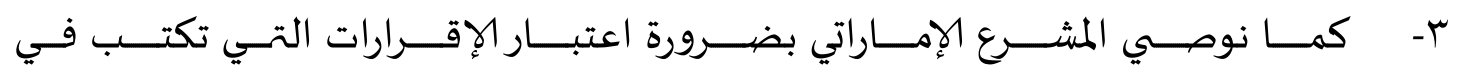

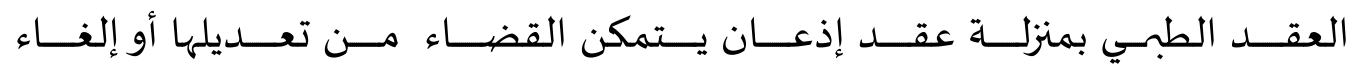

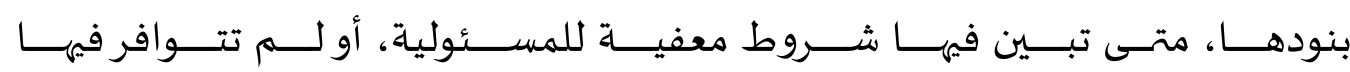
ضمانات الحماية القانونية للمريض كطرف مذعن للعقد .

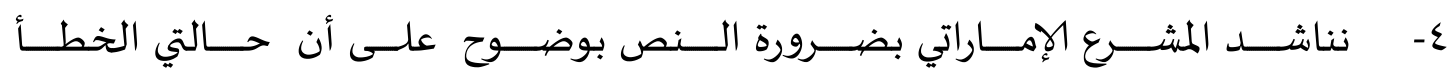

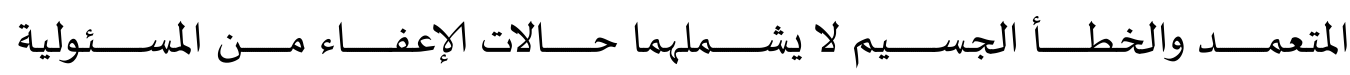
الطبية.

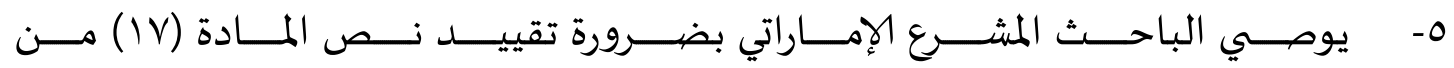

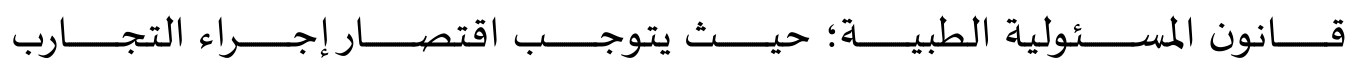
الجديدة في العلاج في حال عدم توافروسـائل علاجية بديلة.

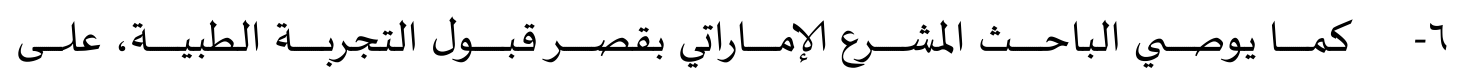
من كان ميؤساً من حياتاه وأصبح أمله ضعيفاً في الحياة . 


\section{الهوامش}

(1)Bonnie F. Fremgen, Medical law and Ethics, Translate: Nageeb Alhasady (New jersey: published by person education,2013), 3rd Edition: p 244 .

(2) (It frequently happens that in the course of making a contract one person delivers to another a document which purports to set out the terms of the contract or refers to other documents in which the terms are set out, and which limits or excludes the liability of the party delivering it ) Perrins,Rand Stuart,P, Mercantile law( HFLPublishers LTD,1975) Fourteenth ed, p: 26.

(Y)عبد الرزاق السنهوري: الوجيز في النظرية العامة للالتزام ( الإسكندرية :دار منشأة المعارف بالاسكندرية،

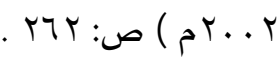

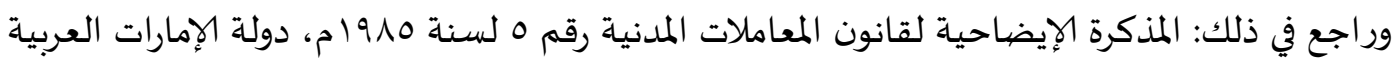

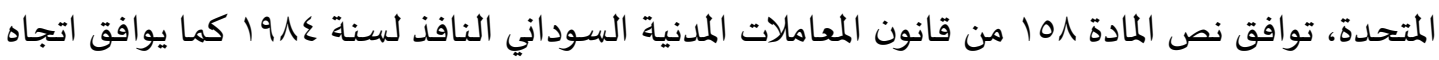

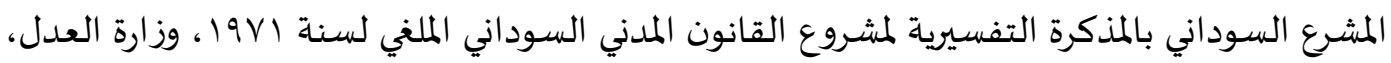

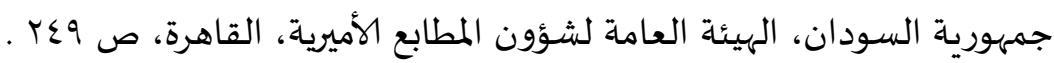

(ع) ولذلك قيل إن الضمان يرفح عن الطبيب في حالة حصول الضرر بحصول آفة سماوية استنادا لقوله

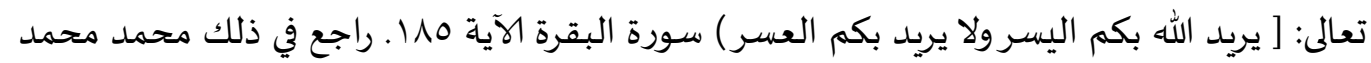

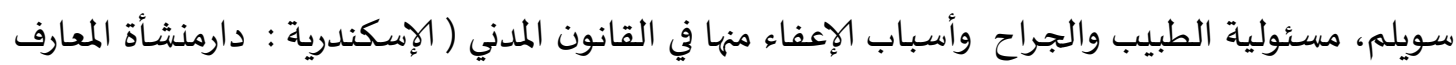

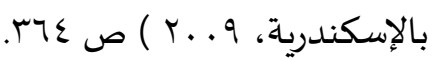

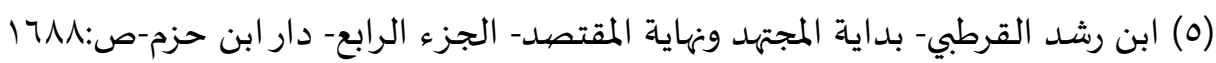

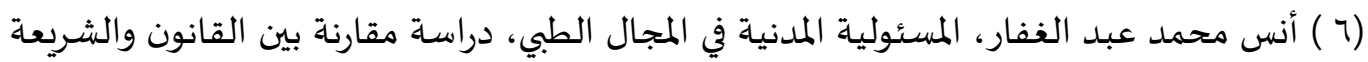

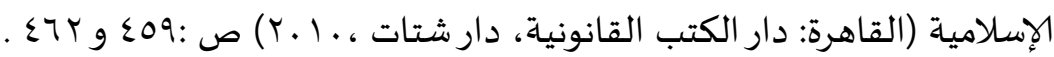

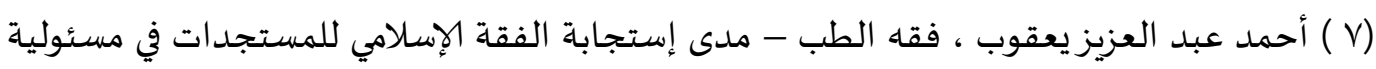

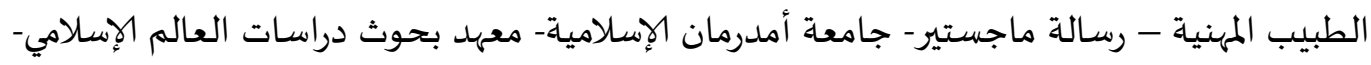
. Tr. Th

(1 )نص المشرع الإماراتي بموجب المادة 197 ع على أنه: يقع باطلا كل شرط يقضي بالإعفاء من المسئولية

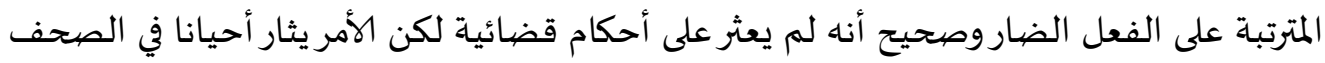

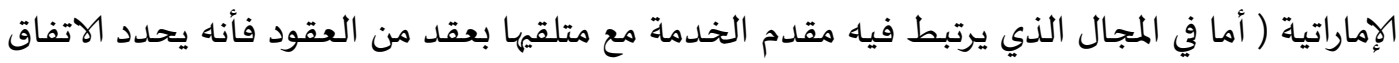

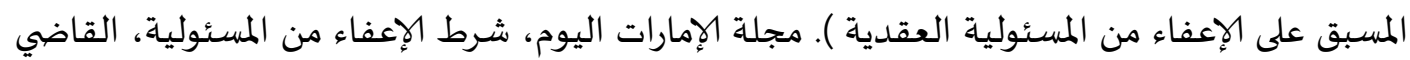

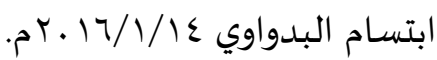

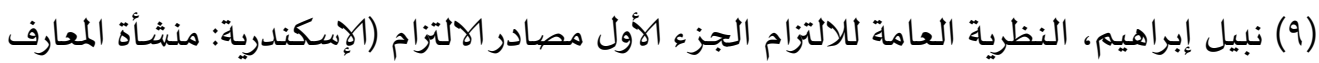

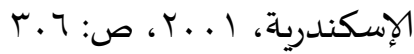
(. (1) علي المهداوي، الوجيز في شرح قانون المعاملات المدنية الاتحادي، أحكام الالتزام (عمان: إثراء للنشر

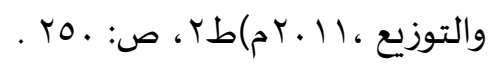




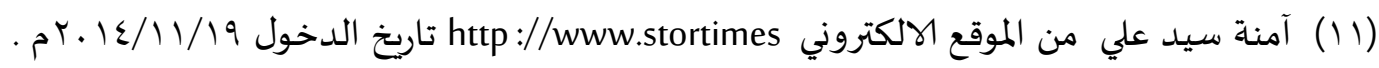

$$
\begin{aligned}
& \text { (Y ( )راجع في ذلك: د. عبد الرحمن شرفي، رؤي حول مدى المسؤولية عن الخطأ الطبي، بحث منشور في }
\end{aligned}
$$

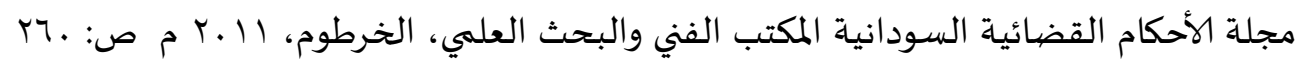

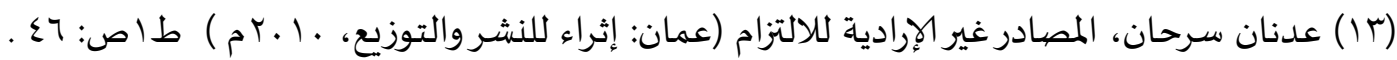

$$
\begin{aligned}
& \text { (ع ا) احمد محمود سعد: مسئولية المستشفى الخاص عن أخطاء الطبيب ومساعدياه ( القاهرة، دار }
\end{aligned}
$$

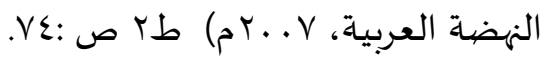

$$
\begin{aligned}
& \text { (10 ) السنهوري، الوجيز في النظرية العامة للالتزام ، مرجع سابق، ص :7؟. } \\
& \text { (17 ) أن مناط مسئولية المتبوع عن أعمال التابع هو أن يكون للمتبوع سلطة فعلية في إصدار الأوامر للتابع } \\
& \text { في طريقة عمله وفي الرقابة عليه في تنفيذ الأوامروالتعليمات .حكم المحكمة الاتحادية العليا، دولة الإمارات } \\
& \text { العربية المتحدة، الطعنان رقم } 10 \text { و } 17 \text { لسنة } 17 \text { مدني . }
\end{aligned}
$$

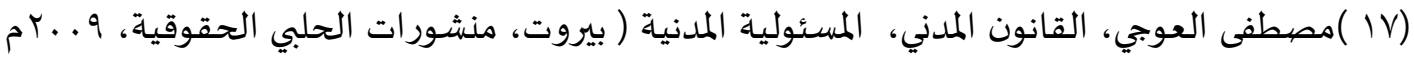

$$
\begin{aligned}
& \text { طל ج: }
\end{aligned}
$$

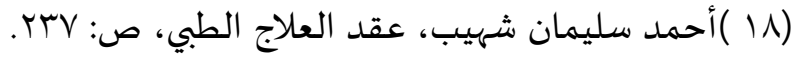

$$
\begin{aligned}
& \text { (19 )غادة فؤاد مجيد المختار، حقوق المريض في عقد العلاج الطبي في القانون المدني، دراسة مقارنة، }
\end{aligned}
$$

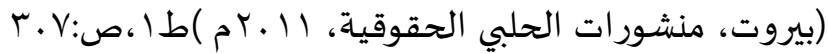

(20) (.. Historically, medical culture couple with provider fear of medical liability law suits has meant that most providers have been reluctant to discuss these Issues openly with patient. This culture of nondisclosure has been reinforced by liability in surer, some of whose personnel instruct providers the insure not to discuss adverse events with patient or others)

Oregon Medical Liability task force report and recommendations -( submitted to the Oregon health policy boord 2010) page: 10 .

(21)(.. Disclosure is useful whether or not it is required. If facilities patient participation in decision - making about their care and enables if formed consent. In addition, organizations with a culture that fosters discussion of mishaps are better positional to explore the causes of patient and prevent avoidable recurrences Disclosure may be a good business practice as well: Research suggests that disclosure of errors to patient may reduce rather than Increase the incidence of law suit and when disclosure is couple with early offers of compensation, it may reduce litigation costs and the size of indemnity payments ).

Oregon medical liability task farceport and recommendation - op. cit. page 16 ,

(22) An exemption clause is a clause wich seeks either to exclude poetry's liability for breach or to limit that liability to a specified amount. Exemption clauses may alternatively seek to exclude or limit the remedies that would otherwise be available for breach or seek to deny that any breach of contract or breach of a duty of care has arisen)22. Jill poole - contract law ،oxford - university press New York 2008) 9th Edition - on line recourse center -) p: 267. 
(23) (Exculpatory agreement between physicians and patients appear to relieve the physician of liability for negligence) Lega/Medicine (Pennsylvania,_American college of legal Medicine 2004)- six edition -p: 330 .

(24) George. D. Pozgar ,legalAspects of health care administration (London Jons and Bort let Publishers,2003) Eighth edition, -p: 290.

(25) Further, my physician has fully explained to me the possibilities of reactions and the possible side effects of the treatment. I under standing all of the foregoing, I herby release the physicians and staff of the department of radiation oncology and William Beaumont hospital from all suits, claims liability or demands of every kind and characters which I or my heirs ...

(.. In early 1989 Cudnik returned to the hospital complaining of back discomfort where upon he was diagnosed as suffering from a post radiation ulcer burn at the site where he previously received radiation treatment .... The court of appeals held in this case that the exculpatory agreement executed by patient prior to receiving radiation therapy was invalid and unenforceable to absolve a medical care provider from liability for medical Mal Practice the agreement in this case is clearly against public policy) Georege D. Pozgor. op.cit. p: 289.

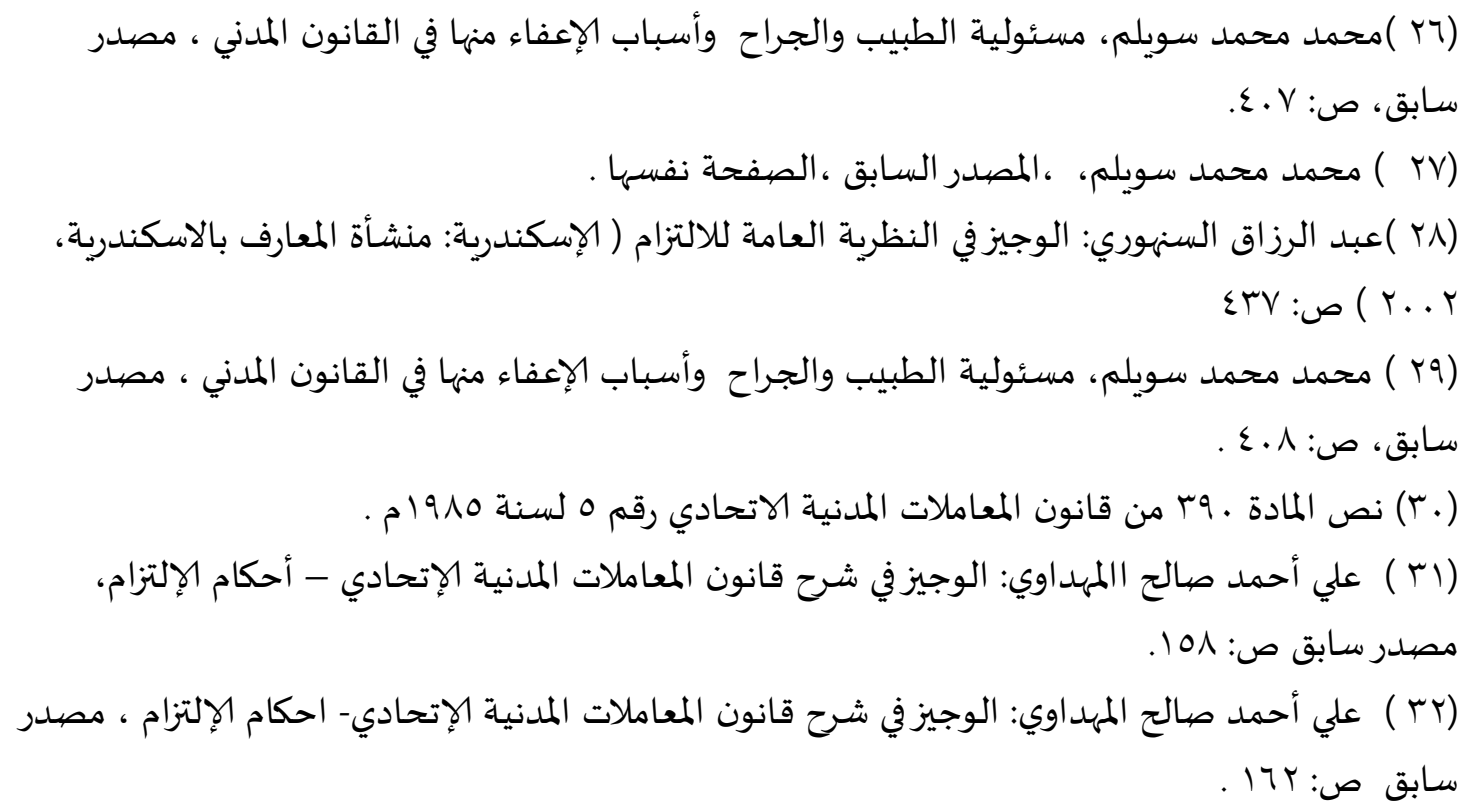

(33) (A hospital may agree to pay (Indemnify) any damages incurred by president of its medical staff for any liability resulting from caring out the duties of that office ). LegalMedicine - op cit p: 330.

(34) (Because it is sometimes difficult to determine the extent of the losses when damages are claimed, the parties often expressly agree at the time of concluding the contract that, if one of the 
parties should commit breach of contract, he will pay a predetermined amount of a money to the other party. This amount is considered a penalty, he has to pay for breaching the contract and, there for a clause of this nature is known as a penalty clause. MA, Fouché, D collier - Reed , CB Ncube T shon wetter, $\mathrm{H}$ jvan As - Legal Principles of contacts and commercial law (cape town :By inter pak Books Peterman zburg, 2010) Eight edition, P: 120.

$$
\text { (ro) بل أن الباحث وجد من السوابق القضائية ما يشير لتشديد المسئولية على الطبيب حتى بأسلوب }
$$

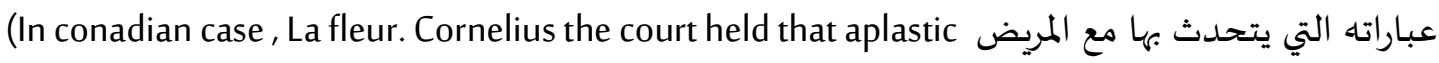
surgeon was bound to an express contractual warranty that he had made to the patient. This warranty a rose when he was a wise enough to say - they will be no problem. (You will be very happy) Mason and MC call smith's. op.cit p:302.

$$
\begin{aligned}
& \text { ( (r) ) دريد محمد علي النظرية العامة للإلتزام، مصدر سابق ص: } 10 \text { ـ ـ }
\end{aligned}
$$

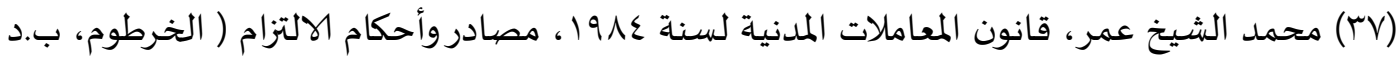

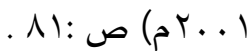

$$
\begin{aligned}
& \text { ( ) المذكرة الإيضاحية لقانون المعاملات المدنية لدولة الإمارات العربية المتحدة، قانون رقم ه لسنة } \\
& \text {. } 1910 \\
& \text { (9 ) راجع المذكرة الإيضاحية لقانون المعاملات المدنية لدولة الإمارات العربية المتحدة، ص: هبا . . }
\end{aligned}
$$

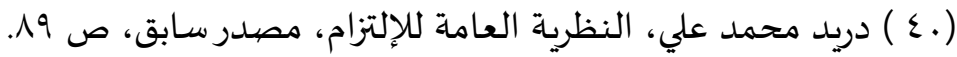

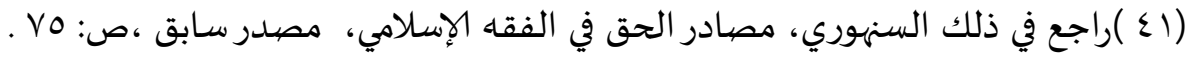

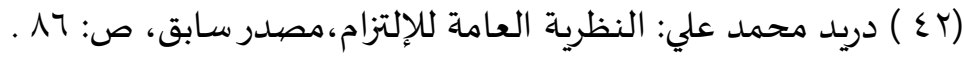

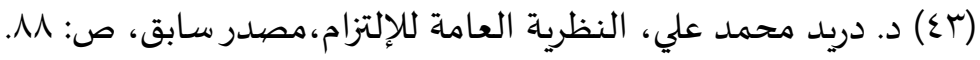

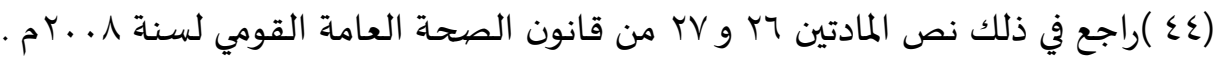

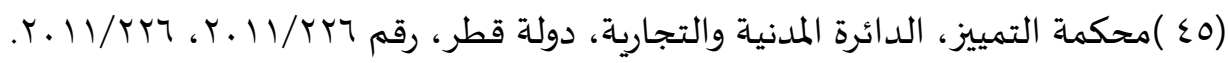

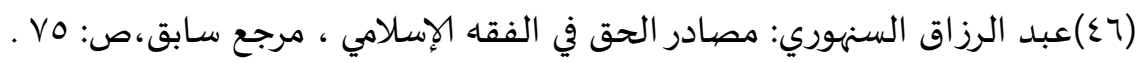

(47) (He may have to accept the terms drawn up by the other party, if the terms are un acceptable , that person will be resigned to not obtaining the product from this source. For this reason standard form contracts are some times called contract of adhesion ). Jill poole. op-cit p: 270.

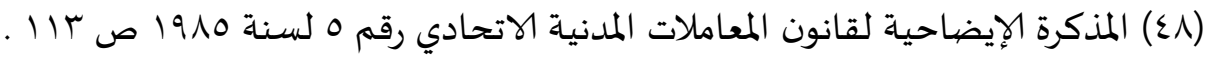

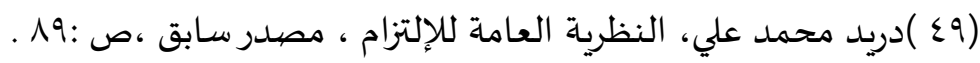

(50) (If the other party has agreed to the terms, he is naturally bound by them) Perrins, R and sturt. op. cit. p:26. 


\section{المصيادر}

أولاً المراجِع العربية

I. ابن رشـد القرطبي- بداية المجتهد ونهاية المقتصد- الجزء الرابع- دار ابن حزم. IIأ أحمد عبد العزيزيعقوب- فقه الطب، مدى إستجابة الفقه الإسلامي للمستجدات في مسئولية الطبيب المهنية- جامعة أمدرمان الإسلامية- معهد بحوث دراسات العالم الإسلامي( رسالة

$$
\text { ماجستير)،.... }
$$

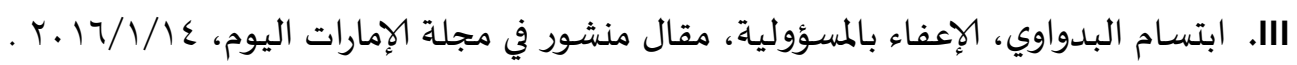

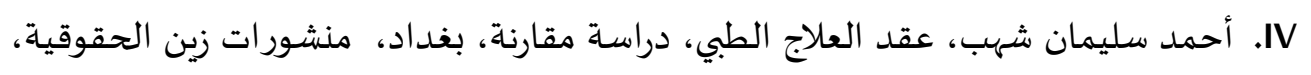

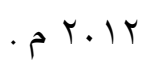

V . احمد محمود سعد: مسئولية المستشفى الخاص عن أخطاء الطبيب ومسـاعديه، طץ، القاهرة،

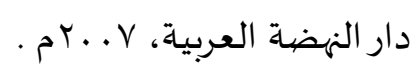

أنس محمد عبد الغفار: المسئولية المدنية في المجال الطبي، دراسة مقارنة بين القانون والشريعة

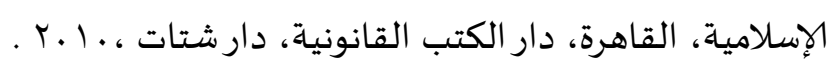

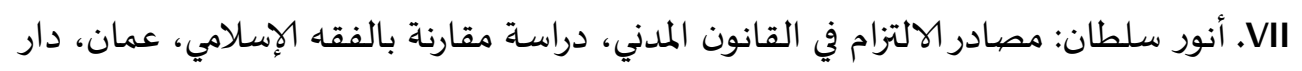

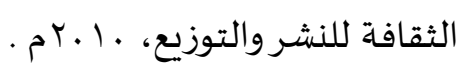

VIII دريد محمد علي: النظرية العامة للالتزام، مصادر الالتزام، دراسة تحليلية مقارنة، منشورات الحلبي

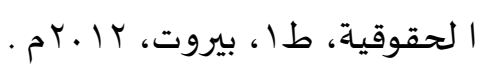

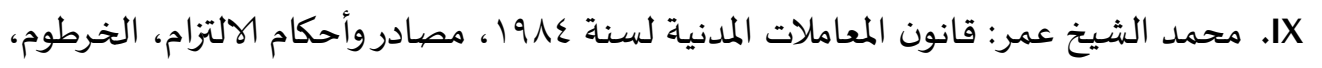

$$
\text { r...l }
$$

Xحمد صالج علي: شرح قانون المعاملات المدنية السوداني لسنة ع191 ، الجزء السادس، الخرطوم،

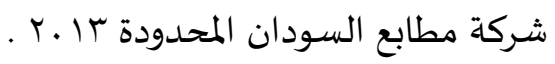

II محمد محمد سويلم: مسئولية الطبيب والجراح وأسباب الإعفاء منها في القانون المدني والفقاء

الإسلامي، دراسـة مقارنة ط ا ، الإسكندرية، منشأة المعارف الإسكندرية، و . . r . )

XII مصطفى العوجي، القانون المدني، المسئولية المدنية (منشورات الحلبي الحقوقية،

$$
\text { .r: }
$$

XIII

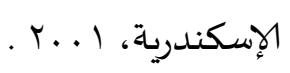

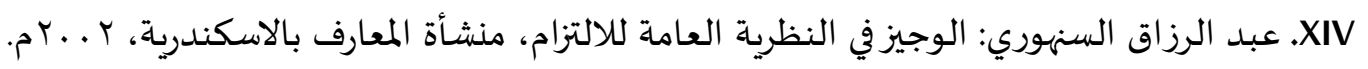

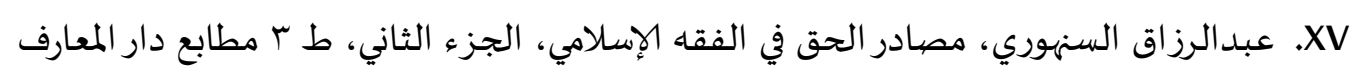

بمصر، 197V. 
XVI

XVII

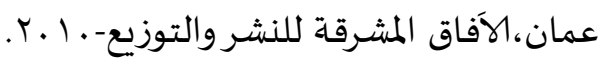

XVIII

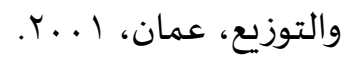

XIX غادة فؤاد مجيد المختار: حقوق المريض في عقد العلاج الطبي في القانون المدني، دراسة مقارنة،

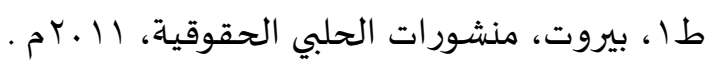

\section{ثانياً المراجع باللغة الأنجليزية}

I. Bonnie F. Fremgen, Medical law and Ethics - New jersey published by person education,2013) $3^{\text {rd }}$ Edition.

II. Perrins, R and Stuort, P,Mercantile I HFL publishers LTD aw, 1975) Fourteenth ed

III. Oregon Medical Liability task force report and recommendations, submitted to the Oregon health policy boord,2010

IV. George. D. Pozgar, legal Aspects of health care administration . (London:, Jons and Bort let Publishers) Eightn edition, 2003 ).

V. Jill poole - contract law (oxford $9^{\text {th }}$ Edition - on line recourse centre -- university press NewYork,2008.)

VI. Lega/Medicine(American college of legal Medicine - six edition - Pennsylvania , 2004)

VII. J. K. Mason. G. T. Laurie - Law and medical ethics (New York seven edition,2006)

VIII. MA, Fouché , D collier - Reed , CB Ncube T shon wetter , H jvan As - (Legal Principles of contacts and commercial law (cape town: By inter pak Books Peterman zburg Eight edition,2015)

\section{ثالثاً: القوانين والمذكرات الإيضاحية.}

ا. قانون المعاملات المدنية الاتحادي رقم 0 لسنة 1910 دولة الإمارات العربية المتحدة.

II. المذكرة الإيضاحية لقانون المعاملات المدنية الاتحادي رقم 0 لسنة 1910. 
اIIا. قانون المعاملات المدنية السوداني: قانون صدر كأمر مؤقت رقم 7 لسنة ع191 وتأيد وأصبح قانون رقم 1 لسنة ع1919

IV قانون قواعد وآداب السلوك للمهن الطبية السوداني لسنة 1979 م جمهورية السودان . V قانون المسئولية الطبية، قانون اتحادي رقم • السنة م . . آم دولة الإمارات العربية المتحدة. المذكرة التفسيرية لمشروع القانون المدني السوداني الملغي لسنة الما اوزارة العدل جمهورية السودان، الهيئة العامة لشؤون المطابع الأميرية، القاهرة .

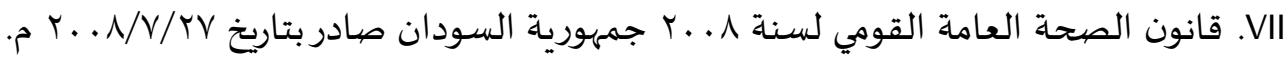

\section{رابعاً: الأحكام القضائية}

ا. حكم المحكمة الاتحادية العليا، دولة الإمارات العبية المتحدة، الطعنان رقم 10 و 17 لسنة 17

$$
\begin{aligned}
& \text { مدني. }
\end{aligned}
$$

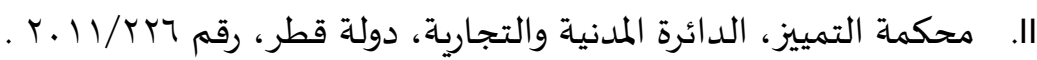

$$
\begin{aligned}
& \text { III. المحكمة العليا جمهورية السودان، حامد محمد الحسن ضد ورثة علية عبد الحميد رقم م ع / } \\
& \text {. ط م م }
\end{aligned}
$$

IV. Cudnik V. William Beaumont hospital.

V. La fleur v.Cornelius. 